\title{
Dynamics of Elongation Factor 2 Kinase Regulation in Cortical Neurons in Response to Synaptic Activity
}

\author{
Justin W. Kenney, ${ }^{1}$ Oksana Sorokina, ${ }^{2}$ Maja Genheden, ${ }^{1}$ Anatoly Sorokin, ${ }^{3}$ J. Douglas Armstrong, ${ }^{2}$ \\ and ${ }^{-C}$ Christopher G. Proud ${ }^{1}$ \\ ${ }^{1}$ University of Southampton, Centre for Biological Sciences, Southampton, SO17 1BJ, United Kingdom, ${ }^{2}$ University of Edinburgh, School of Informatics, \\ Edinburgh, EH8 9AB, United Kingdom, and 'Institute of Cell Biophysics, Pushchino, 142290, Russia
}

The rapid regulation of cell signaling in response to calcium in neurons is essential for real-time processing of large amounts of information in the brain. A vital regulatory component, and one of the most energy-intensive biochemical processes in cells, is the elongation phase of mRNA translation, which is controlled by the $\mathrm{Ca}^{2+} / \mathrm{CaM}$-dependent elongation factor 2 kinase (eEF2K). However, little is known about the dynamics of eEF2K regulation in neurons despite its established role in learning and synaptic plasticity. To explore eEF2K dynamics in depth, we stimulated synaptic activity in mouse primary cortical neurons. We find that synaptic activity results in a rapid, but transient, increase in eEF2K activity that is regulated by a combination of AMPA and NMDA-type glutamate receptors and the mitogenactivated protein kinase (MEK)/extracellular signal-regulated kinase (ERK) and mammalian target of rapamycin complex 1 (mTORC1) pathways. We then used computational modeling to test the hypothesis that considering $\mathrm{Ca}^{2+}$-coordinated MEK/ERK, mTORC1, and eEF2k activation is sufficient to describe the observed eEF2K dynamics. Although such a model could partially fit the empirical findings, it also suggested that a crucial positive regulator of eEF2K was also necessary. Through additional modeling and empirical evidence, we demonstrate that AMP kinase (AMPK) is also an important regulator of synaptic activity-driven eEF2K dynamics in neurons. Our combined modeling and experimental findings provide the first evidence that it is necessary to consider the combined interactions of $\mathrm{Ca}^{2+}$ with MEK/ERK, mTORC1, and AMPK to adequately explain eEF2K regulation in neurons.

Key words: AMPK; bicuculline; dynamical systems; ERK; mTORC1; translation elongation

\section{Introduction}

The fast and dynamic regulation of cell signaling cascades by $\mathrm{Ca}^{2+}$ in neurons is integral for a variety of neurophysiological processes (Bading, 2013), such as the modulation of the machinery involved in protein synthesis (Costa-Mattioli et al., 2009). Protein synthesis involves three phases, initiation, elongation, and termination, with the elongation phase being regulated by the $\mathrm{Ca}^{2+} /$ calmodulin (CaM)-dependent elongation factor $2 \mathrm{ki}$ nase (eEF2K; Kenney et al., 2014), thus making it the step most directly regulated by $\mathrm{Ca}^{2+}$. eEF2K phosphorylates eEF2 at T56,

Received July 12, 2014; revised 0ct. 23, 2014; accepted Nov. 18, 2014.

Author contributions: J.W.K., 0.S., J.D.A., and C.G.P. designed research; J.W.K., 0.S., and M.G. performed research; A.S. contributed unpublished reagents/analytic tools; J.W.K. analyzed data; J.W.K. and 0.S. wrote the paper. The authors declare no competing financial interests.

This work was supported by European Research Area Net systems biology (SYNSYS), Israel Science Foundation Grant 1003/12 (principal investigator, Kobi Rosenblum), Biotechnology and Biological Sciences Research Council Grants BB/I004483/1 (C.G.P.) and BB/1004491/1 (J.D.A.), Wellcome Trust Grant 086688 (C.G.P.), and European Union Seventh Framework Programme HEALTH-F2-2009-241498 (European Consortium on Synaptic Protein Networks in Neurological and Psychiatric Diseases) (J.D.A.). We thank Vincent $0^{\prime}$ Connor for helpful discussions.

This article is freely available online through the J Neurosci Author Open Choice option.

Correspondence should be addressed to either of the following: Christopher Proud, University of Southampton, Centre for Biological Sciences, Southampton, S017 1BJ, UK, E-mail: C.G.Proud@soton.ac.uk; or Douglas Armstrong, University of Edinburgh, School of Informatics, Edinburgh, EH8 9AB, UK. E-mail: douglas.armstrong@ed.ac.uk.

DOI:10.1523/JNEUROSCI.2866-14.2015

Copyright $\odot 2015$ Kenney et al.

This is an Open Access article distributed under the terms of the Creative Commons Attribution License (http://creativecommons.org/licenses/by/3.0), which permits unrestricted use, distribution and reproduction in any medium provided that the original work is properly attributed. which impairs its ability catalyze ribosomal translocation, thereby slowing overall rates of elongation (Nairn and Palfrey, 1987; Price et al., 1991). Moreover, eEF2K has been implicated recently in a variety of neuronal functions, such as synaptic plasticity, learning and memory, cytoprotection, and ischemia (Park et al., 2008; Im et al., 2009; Gildish et al., 2012; Romero-Ruiz et al., 2012; Leprivier et al., 2013). Although previous work has found that stimuli that increase $\mathrm{Ca}^{2+}$ influx in neurons, such as elevated synaptic activity, can result in an increase in eEF2 phosphorylation (Lenz and Avruch, 2005; Verpelli et al., 2010; Heise et al., 2014), the complex dynamics of eEF2K regulation have not been explored.

In addition to positive regulation by $\mathrm{Ca}^{2+} / \mathrm{CaM}$, a number of signaling pathways have been found to negatively regulate eEF2K activity, such as the mammalian target of rapamycin complex 1 (mTORC1) and mitogen-activated protein kinase (MEK)/extracellular signal-regulated kinase (ERK) pathways (Kenney et al., 2014). In neuronal preparations, the mTORC1 pathway has been studied extensively as a negative regulator of eEF2K in neurons (Carroll et al., 2004; Inamura et al., 2005; Weatherill et al., 2011), whereas the MEK/ERK pathway has received comparatively little attention (Belelovsky et al., 2005; Kanhema et al., 2006) but has been studied more thoroughly in non-neuronal preparations (Wang et al., 2001; Wang and Proud, 2002). Importantly, synaptic activity-induced stimulation of mTORC1 and MEK/ERK in neurons requires $\mathrm{Ca}^{2+}$ influx (Lenz and Avruch, 2005; Wang et 
al., 2007), suggesting that elevated $\mathrm{Ca}^{2+}$ can result in both the activation and inhibition of eEF2K activity. However, it is not known whether $\mathrm{Ca}^{2+}$-orchestrated mTORC1 and MEK/ERK pathway activation is sufficient to describe the effects of increased synaptic activity on eEF2K dynamics.

We find that elevating synaptic activity in cortical neurons results in a rapid and transient increase in eEF2 phosphorylation that depends on AMPA and NMDA-type glutamate receptors (GluRs) and a decrease that depends on the MEK/ERK and mTORC1 pathways. We then used an ordinary differential equation (ODE) model to test the hypothesis that $\mathrm{Ca}^{2+}$-coordinated regulation of eEF2K, MEK/ERK, and MTORC1 would be sufficient to explain the observed eEF2K dynamics. This initial model captured much of eEF2K dynamics; however, it also indicated that an additional regulatory element was necessary. We used the model to predict the activation profile of the missing regulator. We found that synaptic activity-induced AMP kinase (AMPK) activation fits the prediction and that AMPK is indeed a positive regulator of eEF2K in neurons. Overall, we provide the first evidence that synaptic activity-driven eEF2K dynamics in neurons arises from $\mathrm{Ca}^{2+}$-coordinated interactions of eEF2K with the MEK/ERK, mTORC1, and AMPK pathways.

\section{Materials and Methods}

Reagents. Neurobasal medium, B27, and L-glutamine were obtained from Life Technologies. Papain was from Worthington Biochemical. Bovine serum albumin (BSA), soybean trypsin inhibitor (STI), L-cysteine, D-2amino-5-phosphonopetanoic acid (APV), EGTA, nifedepine, 2,3-dihydroxy-6-nitro-7-sulfonyl-benzo[f] quinoxaline (NBQX), $\alpha$-methyl-(4-carboxyphenyl)glycine (MCPG), and bicuculline were from Sigma. MycoZap was from Lonza. Rapamycin was from Millipore, AZD6244 [6-(4-bromo-2-chlorophenylamino)-7-fluoro- $N$-(2-hydroxyethoxy)-3-methyl-3H-benzo[d]imidazole-5-carboxamide] was from Selleck Chemicals, and A769662 [6,7-dihydro-4-hydroxy-3-(2'hydroxy [1,1'-biphenyl]-4-yl)-6-oxo-thieno[2,3-b] pyridine-5-carbonitrile] was from Tocris Bioscience. The anti-phosphorylated (p) eEF2 (T56) antibody was custom made by Eurogentec. Antibodies for eEF2 (catalog \#2332), p-ERK T202/Y204 (catalog \#4370), p-ribosomal protein S6 (p-S6) S240/244 (catalog \#2215), p-acetyl-CoA carboxylase (ACC; catalog \#3661), p-AMPK T172 (catalog \#2535), and AMPK (catalog \#2532) were purchased from Cell Signaling Technologies; antibodies for glyceraldehyde 3-phosphate dehydrogenase (GAPDH; catalog \#G8795) and tubulin (catalog \#T6199) were from Sigma. The antibody for total S6 was from either Cell Signaling Technologies (catalog \#2317) or Santa Cruz Biotechnology (catalog \#sc-74459).

Primary neuronal cell culture. Primary cultures of cortical neurons were isolated as described previously (Wong et al., 2005). Cortices were isolated in ice-cold HBSS from P0 or P1 C57BL/6J mice of either sex. All procedures involving mice were done in accordance with United Kingdom Animals (Scientific Procedures) Act 1986. Tissue was gently minced and digested in Neurobasal medium containing papain $(20 \mathrm{U} / \mathrm{mL})$ and $0.32 \mathrm{mg} / \mathrm{mL} \mathrm{L}$-cysteine at $37^{\circ} \mathrm{C}$ for $20 \mathrm{~min}$, followed by $31^{\circ} \mathrm{C}$ for an additional $20 \mathrm{~min}$. Tissue was then washed once in Neurobasal medium containing $1 \mathrm{mg} / \mathrm{mL}$ each of BSA and STI and then incubated at $37^{\circ} \mathrm{C}$ for $2 \mathrm{~min}$ in Neurobasal medium containing $10 \mathrm{mg} / \mathrm{mL}$ each of BSA and STI. The dissociated tissue was then washed once in Neurobasal medium and triturated with fire-polished glass pipettes. Cells were then washed in Neurobasal medium and passed through a $40 \mu \mathrm{m}$ cell strainer, after which they were plated onto poly-D-lysine-coated culture dishes at high density (1500-2000 cells $\left./ \mathrm{mm}^{2}\right)$. After $1 \mathrm{~h}$, overlying medium was removed and replaced with Neurobasal medium containing 2\% B27 supplement, $0.5 \mathrm{mM}$ L-glutamine, and either $100 \mathrm{U} / \mathrm{mL}$ penicillin/ streptomycin or $1 \times$ MycoZap. One-half of the medium was replaced with fresh medium every 3-4 d. Cells were used in experiments at 10-12 DIV.

Drugs were added to neuronal cultures by diluting into $500 \mu \mathrm{l}$ of overlying medium before addition to the culture plate to ensure rapid and even diffusion. APV $(100 \mu \mathrm{M})$, nifedepine ( $5 \mu \mathrm{M})$, MCPG $(100 \mu \mathrm{M})$, and NBQX $(10 \mu \mathrm{M})$ were added $20-30 \mathrm{~min}$ before bicuculline $(50 \mu \mathrm{M})$ stimulation unless otherwise noted. AZD6244 $(10 \mu \mathrm{M})$ was added $30 \mathrm{~min}$ and rapamycin (100 nM) and A769662 (100 $\mu \mathrm{M}) 60 \mathrm{~min}$ before the indicated treatments. EGTA ( $5 \mathrm{~mm}$ ) was applied for $10 \mathrm{~min}$.

SDS-PAGE. The overlying medium was removed, and cells were lysed via addition of $95^{\circ} \mathrm{C} 1 \times$ Laemmli's sample buffer. Cell lysates were vortexed vigorously for $10 \mathrm{~s}$ and centrifuged for $15 \mathrm{~min}$ at $20,000 \times \mathrm{g}$. After boiling for $5 \mathrm{~min}$, equal amounts of each sample were resolved on $12.5 \%$ polyacrylamide gels and transferred to a nitrocellulose membrane $(0.45$ $\mu \mathrm{m}$ pore size) via electroblotting. Membranes were blocked in $5 \%$ nonfat dry milk or $2 \%$ BSA in either PBS containing $0.1 \%$ Tween (PBST) or Tris-buffered saline containing $0.1 \%$ Tween (TBST) at room temperature for $45 \mathrm{~min}$, washed, and then incubated with primary antibody in PBST or TBST containing 2\% BSA for $1 \mathrm{~h}$ at room temperature or overnight at $4^{\circ} \mathrm{C}$. After washing, membranes were incubated with appropriate secondary antibodies in PBST and 2\% BSA and imaged using the LI-COR Odyssey infrared imaging system.

Statistical analyses. Immunoblot data were quantified using LI-COR Odyssey software (version 3.0), and experimental treatments were expressed relative to cells that received no treatment. Data were analyzed using one-way ANOVAs or two-way ANOVAs as appropriate and followed up by Dunnett's post hoc $t$ tests with untreated neurons as the comparison group. If only two groups were compared, independent samples $t$ tests were performed. SPSS version 20.0.0 (IBM) was used for all statistical analyses.

Modeling. The model was developed in Systems Biology Toolbox 2 (SBTOOLBOX2; version Rev1176, R2012a) for MATLAB (version 7.11.1, R2010) and fitted with simplex and simulated annealing optimization algorithms from the SBPD package in SBTOOLBOX2 (Schmidt and Jirstrand, 2006; Banks et al., 2008). Throughout the model, MichaelisMenten kinetics was used to describe the enzymatic reactions of phosphorylation and dephosphorylation, and the law of mass action was used to describe protein binding and unbinding. A more detailed account of the modeling is available as supplemental material.

The model included three conceptual building blocks: (1) an ERK module, (2) an mTORC1 module, and (3) an eEF2K module. Interactions in the model were built based on known interactions of the different module components with the MEK/ERK and MTORC1 modules providing combined inhibitory action on eEF2K with no feedback. We started by fitting parameters for the frame model (MEK/ERK and mTORC1 modules only) in response to the application of bicuculline. During the procedure, parameters were allowed to change within biologically plausible ranges provided by literature when available. The frame model was fitted simultaneously to time series curves for p-ERK and p-S6 kinase 1 (S6K1; p-S6 240/244 data were used as an indicator of S6K1 activity). After adding eEF2K to the model, the parameters for the MEK/ERK and mTORC1 modules were not allowed to vary $>50 \%$ from their initial values and were fitted again to the same set of experimental data, now including three readouts (p-ERK, p-S6K1, and p-eEF2). During this second fitting, only parameters for eEF2K were allowed to change in the biologically plausible range. A third round of fitting included the unperturbed and perturbed experimental conditions (i.e., with and without AZD6244 or rapamycin); thus, five experiments were finally fitted simultaneously while parameters were allowed to change within $50 \%$ of their previously obtained values.

MEK/ERK submodel. Because the MEK/ERK pathway has been an attractive target for modelers for many years, we made use of an existing MEK/ERK model from the BioModels Database (identification number BIOMDB0000000084; Hornberg et al., 2005). We chose this model because it has a compact pathway that matched the detail used in our overall model. We modified the original model to explicitly include protein phosphatase 2A (PP2A)-dependent dephosphorylation of MEK and ERK based on the fact that PP2A is known act on both this pathway (Alessi et al., 1995) and eEF2 (Redpath et al., 1993). Although $\mathrm{Ca}^{2+}$-stimulated phosphatases, such as calcineurin, would have fit well into our $\mathrm{Ca}^{2+}$. coordinated model, calcineurin has limited substrate specificity and is not known to dephosphorylate any of the components considered in the model (Li et al., 2011). We also included a competitive mechanism for 
inhibition of MEK by AZD6244 (Huynh et al., 2007). Finally, in the most recent version of the model, the cascade was updated based on the study by Caloca et al. (2003) in which we substituted receptor " $R$ " in the Hornberg model to Ras activation by RasGRP in response to elevated $\mathrm{Ca}^{2+}$.

mTORC1 submodel. We did not attempt to describe the overall complexity of the mTORC1 pathway in the model, because there are numerous crosstalking pathways. An overly detailed description would invariably result in the inclusion of a large number of parameters for which we lack exact information and reduce biological plausibility of the model. Given the specific hypothesis under consideration and the experimental data available, we identified key elements in the mechanism that allowed for an accurate reproduction of experimental data with minimal details. Thus, mTORC1 was modeled as being activated by elevated $\mathrm{Ca}^{2+} / \mathrm{CaM}$ based on previous findings (Lenz and Avruch, 2005; Gulati et al., 2008), followed by activation of the complex by phosphorylation. We also included the activation of mTORC1 by the MEK/ERK pathway and mTORC1-stimulated activation of S6K1 and suppression of PP2A (Hui et al., 2005). Inhibition of mTORC1 by rapamycin was modeled as binding to $\mathrm{mTORC} 1$ and preventing its kinase function (Ballou and Lin, 2008).

eEF2K submodel. eEF2K was modeled as being activated by fully occupied $\mathrm{Ca}^{2+} / \mathrm{CaM}$ and dephosphorylation of eEF2 and eEF2K as regulated by PP2A (Redpath et al., 1993). For the inhibition of eEF2K by p-S6K1 and p-ERK, we considered two possible mechanisms: (1) p-ERK and p-S6K1 phosphorylate the eEF2K/Ca ${ }^{2+} / \mathrm{CaM}$-bound complex, which then turns eEF2K to an inactive state; or (2) phosphorylation of eEF2K by p-ERK and p-S6K1 prevent binding of eEF2 $\mathrm{K}_{\text {to }} \mathrm{Ca}^{2+} / \mathrm{CaM}$. The second mechanism was unable to reproduce experimental curves, even when the frame parameters were allowed to change in a wide, biologically plausible range (data not shown). Thus, we made use of the first mechanism described above in building the eEF2K module.

$\mathrm{Ca}^{2+} / \mathrm{CaM}$ interaction. The temporal profile and shape of the bicuculline-induced changes in $\mathrm{Ca}^{2+}$ influx were modeled as an event when intracellular $\mathrm{Ca}^{2+}$ is elevated based on experimental evidence (Bengtson et al., 2013). Both mTORC1 and eEF2K are modeled as activated by $\mathrm{Ca}^{2+} / \mathrm{CaM}$ complex binding. Initially, we used a one-step stoichiometric reaction for $\mathrm{Ca}^{2+} / \mathrm{CaM}$ binding resulting in a shared pool of $\mathrm{Ca}^{2+} / \mathrm{CaM}$ for activation of both pathways. Although this resulted in an accurate fit of some time series data for the framework model, it was insufficient when including eEF2K and experiments using AZD6244 and rapamycin because the mTORC1 and eEF2K systems competed for the restricted pool of $\mathrm{Ca}^{2+} / \mathrm{CaM}$. Considering that the two lobes of CaM have distinct $\mathrm{Ca}^{2+}$ affinities (Faas et al., 2011), we used a two-step binding of $\mathrm{Ca}^{2+}$ to $\mathrm{CaM}$ in which half-bound (i.e., two ions per CaM molecule) and fully bound (i.e., four ions) CaM have different interaction targets. With respect to our model, this means that, at a low concentration of $\mathrm{Ca}^{2+}$, the ions would tend to occupy the two high-affinity binding sites at the $\mathrm{C}$ terminus, whereas during continuous bicuculline treatment, the level of intracellular $\mathrm{Ca}^{2+}$ remains high for $60 \mathrm{~min}$, which allows the full occupation of all four CaM binding sites, including its low-affinity N-terminal lobes. The modeling suggests that half-bound CaM preferentially binds mTORC1, whereas fully bound CaM preferentially binds eEF2K.

AMPK pathway. The AMPK subsystem was added to the initial model to generate a refined model. We used a mechanism in which binding of $\mathrm{Ca}^{2+} / \mathrm{CaM}$ to $\mathrm{Ca}^{2+} / \mathrm{CaM}$-dependent protein kinase kinase- $\beta$ $(\mathrm{CaMKK} \beta)$ is followed by AMPK phosphorylation and activation (Hawley et al., 2005; Woods et al., 2005). As in the case of RasGRP, we allowed both stoichiometric forms of $\mathrm{Ca}^{2+} / \mathrm{CaM}$ to contribute to AMPK phosphorylation and activation with their own constants. The model was built such that p-AMPK activates eEF2K via phosphorylation, leading to increased eEF2 phosphorylation. Activated AMPK is also known to inhibit mTORC1, so an appropriate additional inhibitory term was added to the process describing mTORC1 activation.

Initial conditions. One unique aspect of our fitting approach was in our treatment of initial conditions. We assumed that, before treatments, cells were in homeostasis and thus the model has to be in a steady-state condition. In this case, any parameter modifications would change the steady-state concentrations of the system, and initial concentrations were adjusted accordingly. To account for this, we modified the source code of the optimization part of the SBPD package in such a way that, for each parameter set, first the steady state of the original model was calculated, and its stationary concentrations were used as initial conditions for their respective numerical experiments. The modified code is available on request.

Optimization. To ensure that the parameter set used in the models here is a global minimum of the optimization process, we used a multi-start method in which we repeated the fitting procedure of the final model 1000 times using initial parameter sets distributed uniformly over the entire biologically plausible range. All of these parameter sets resulted in cost functions at least an order of magnitude worse than our result. However, this multi-start method is known to have several weaknesses (Moles et al., 2003). To further test optimization, the 10 best parameter sets from the multi-start method were chosen as initial points for simulated annealing optimization. Although the result of the simulated annealing tests was considerably better than the multi-start method alone, no parameter set yielded a cost function better than our results, suggesting that our set of final parameters are likely to be the global minimum.

Sensitivity analysis. We performed global sensitivity analysis to determine to what degree different modeling parameters contributed to model behavior. We used partial rank correlation coefficients (Marino et al., 2008) in the SBPD package with modifications similar to the optimization protocol (i.e., forcing the algorithm to recalculate the steady state for each parameter set; modified code is available on request), ensuring consistency between the fitting and the sensitivity analysis.

\section{Results}

\section{Bicuculline-induced eEF2 phosphorylation is rapid and dynamic}

To understand the dynamic regulation of eEF2K phosphorylation by synaptic activity in cortical neurons, primary neuronal cultures were stimulated with bicuculline, a GABA receptor antagonist. Bicuculline was chosen as the stimulus because it is known to increase synaptic activity through disinhibition of endogenous neuronal activity present in cultures, whereas direct GluR stimulation of nonsynaptic receptors triggers cell death pathways (Hardingham et al., 2002; Lee et al., 2005; Hardingham and Bading, 2010). Continuous bicuculline treatment resulted in a rapid but transient increase in eEF2 phosphorylation that decayed to baseline levels after $\sim 20 \mathrm{~min}$ of stimulation (Fig. $1 \mathrm{~A}$ ). Given that eEF2K is known to be regulated by the mTORC1 and MEK/ERK pathways (Wang et al., 2001; Carroll et al., 2004; Inamura et al., 2005), we also examined the phosphorylation of ERK1/2 and ribosomal protein S6 at S240/244, readouts of MEK/ ERK and mTORC1 pathways, respectively. We chose the phosphorylation of S6 at S240/244 instead of S235/236 as our readout of the mTORC1 pathway given that $\mathrm{S} 240 / 244$ is specifically regulated by mTORC1, whereas S235/236 is also regulated via p90 ${ }^{\text {RSK }}$, which is downstream of ERK (Pende et al., 2004). Continuous bicuculline treatment resulted in a rapid and sustained increase in ERK phosphorylation and a slower but sustained increase in $\mathrm{S} 6$ phosphorylation in cortical neurons (Fig. $1 B, C$ ). The initial round of model development indicated that the first couple of minutes of bicuculline administration were the most important for adequate parameter value determination, so we repeated the first $10 \mathrm{~min}$ of the time course but with the inclusion of a 30 s time point. This revealed that eEF2, but not ERK, phosphorylation was elevated after $30 \mathrm{~s}$ of bicuculline stimulation (Fig. 1E-H).

\section{GluR involvement in the bicuculline-induced increase in eEF2 phosphorylation}

To determine the processes required for the increase of eEF2 phosphorylation during both the initial and sustained increase of 
A
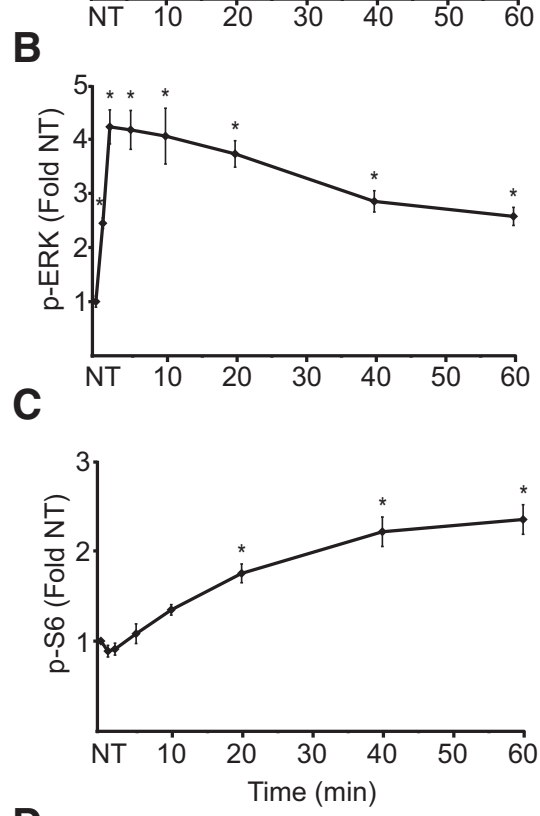

D
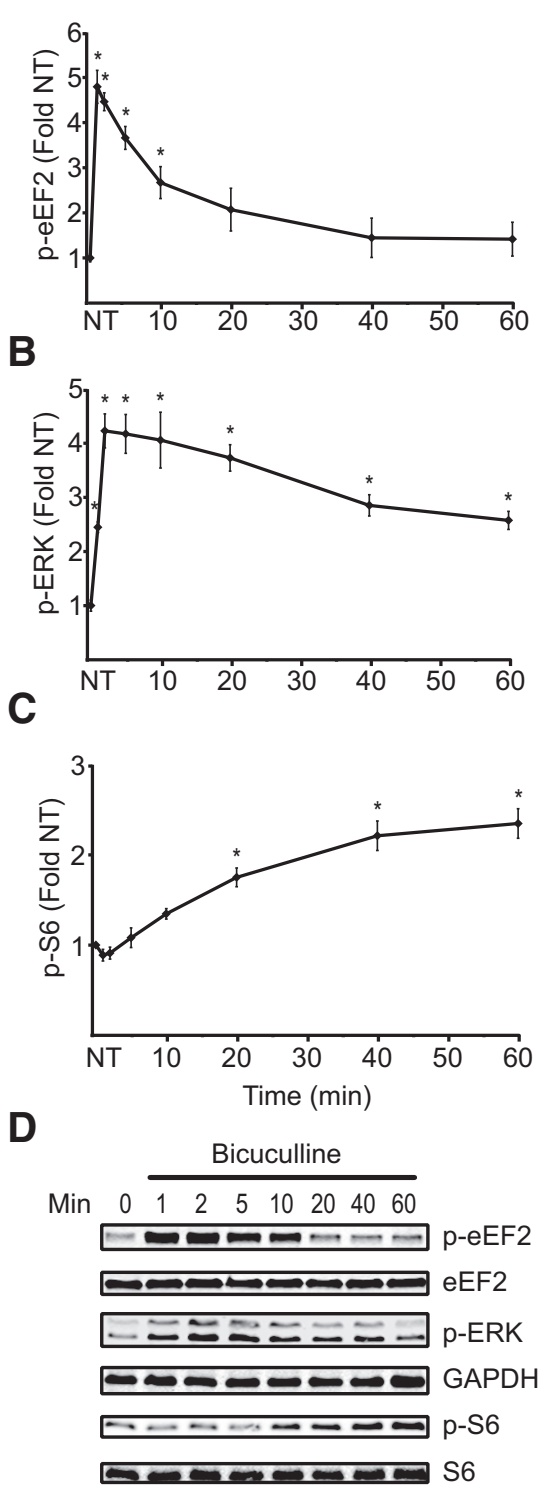

E

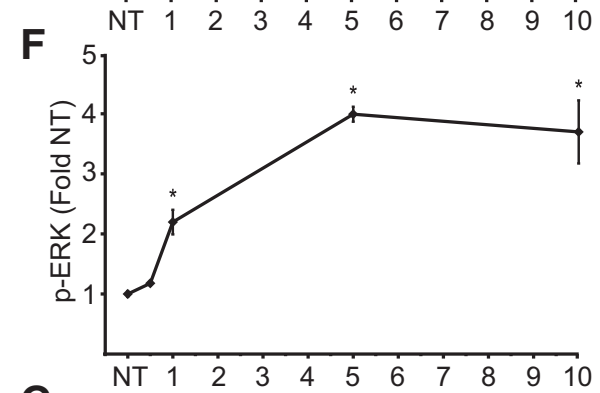

G

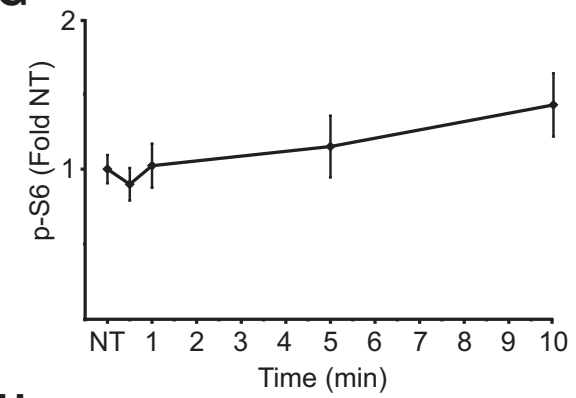

H

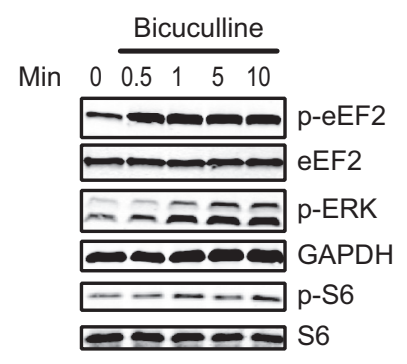

Figure 1. Increasing synaptic activity results in the rapid and dynamic regulation of eEF2 phosphorylation. $A-C$, The effect of continuous bicuculline administration on $\mathrm{p}$-eEF2, p-ERK, and p-S6 (240/244). One-way ANOVAs revealed effects of stimulation on p-eEF2 $\left(F_{(7,27)}=21.1, p<0.001\right)$, p-ERK $\left(F_{(7,27)}=33.1, p<0.001\right)$, and p-S6 $\left(F_{(7,27)}=17.4, p<0.001\right) ; n=4-5 . \mathbf{D}$, Representative Western blots for $\boldsymbol{A}-\boldsymbol{C}$. $\boldsymbol{E}-\boldsymbol{G}$, Replication of the effect of continuous bicuculline administration on $\mathrm{p}$-eEF2, $\mathrm{p}$-ERK, and p-S6 (240/244) over $10 \mathrm{~min}$ including a $30 \mathrm{~s}$ time point. One-way ANOVAs revealed effects of stimulation time on p-eEF2 $\left(F_{(4,23)}=\right.$ $17.9, p<0.001)$ and $p-\operatorname{ERK}\left(F_{(4,23)}=33.4, p<0.001\right)$ but notp-S6 $\left(F_{(4,23)}=1.7, p=0.19\right) ; n=5-6 . \boldsymbol{H}$, Representative Western blots for $\boldsymbol{E}-\boldsymbol{G}$. Data represent mean \pm SEM; ${ }^{*} p<0.05$ compared with untreated neurons (NT).

synaptic activity, we examined GluR involvement both immediately $(1 \mathrm{~min})$ and a short time $(10 \mathrm{~min})$ after the administration of bicuculline. Ten minutes of bicuculline treatment resulted in an increase in eEF2 phosphorylation that was prevented by the previous application of the NMDA receptor (NMDAR) antagonist APV or the AMPA receptor (AMPAR) antagonist NBQX (Fig. 2A). Neither the L-type voltage-gated calcium channel (LVGCC) antagonist nifedipine nor the metabotropic GluR (mGluR) antagonist MCPG prevented the bicuculline-induced increase in eEF2 phosphorylation after 10 min of treatment. We also examined the receptor dependence of the bicucullineinduced increase in ERK phosphorylation and found that this increase is also regulated via NMDA and AMPA-type GluRs (Fig. $2 A$ ). Interestingly, after $1 \mathrm{~min}$ of bicuculline treatment, the syn- aptic activity-induced increase in eEF2 phosphorylation was found to be insensitive to the application of either APV or NBQX alone (Fig. 2B). Furthermore, combining APV with nifedipine was also ineffective, but the combined application of APV, NBQX, and nifedipine was capable of preventing the bicuculline-induced increase in eEF2 phosphorylation after 1 min of stimulation, suggesting that the rapid increase in eEF2 phosphorylation is dependent on combined ion channel signaling. In contrast, the bicucullineinduced increase in ERK phosphorylation after 1 min was sensitive to the blocking of NMDARs and/or L-VGCCs (Fig. 2B). These data suggest that, under basal conditions, eEF2K may be very sensitive to small increases in $\mathrm{Ca}^{2+}$ levels that can occur independently via NMDARs or calcium-permeable AMPARs (Fig. 2B). However, after $10 \mathrm{~min}$ of stimulation, eEF2K activation requires greater $\mathrm{Ca}^{2+}$ influx through both NMDARs and AMPARs (Fig. 2A), suggesting that eEF2K is less active in response to relatively small increases in intracellular $\mathrm{Ca}^{2+}$.

To determine whether an influx of extracellular $\mathrm{Ca}^{2+}$ is necessary for the bicuculline-induced increase in p-eEF2 and p-ERK, we applied a calcium chelator, EGTA, immediately before the administration of bicuculline for 1 or $10 \mathrm{~min}$. EGTA resulted in a significant reduction in the bicuculline-induced increase in both p-eEF2 and p-ERK (Fig. 2C).

\section{Involvement of mTORC1 and ERK in the regulation of eEF2K}

Increased synaptic activity results in a rapid initial increase in eEF2 phosphorylation that is followed by decay back to baseline levels. The decrease in eEF2 phosphorylation back to baseline during prolonged bicuculline stimulation could potentially be attributable to two factors: (1) a decrease in the levels of intracellular calcium resulting in decreased eEF2K activation or (2) an active inhibition of eEF2K by other cell signaling cascades.

To determine whether there are functionally elevated, physiologically active, calcium levels after a prolonged increase in synaptic activity, we observed that ERK phosphorylation remains elevated after $60 \mathrm{~min}$ of bicuculline stimulation and that, at early time points, the bicuculline-induced increase in ERK phosphorylation is prevented by blocking calcium-permeable NMDARs and L-VGCCs (Fig. 2). This suggests that elevated levels of calcium influx may maintain the increase in ERK phosphorylation after 60 min of bicuculline administration, which would indicate functionally elevated levels of calcium at this time point that could also activate eEF2K. To test this hypothesis directly, APV and nifedipine were administered for the last $10 \mathrm{~min}$ of $60 \mathrm{~min}$ of bicuculline administration (Fig. $3 A$ ), resulting in a reversal of the 
A

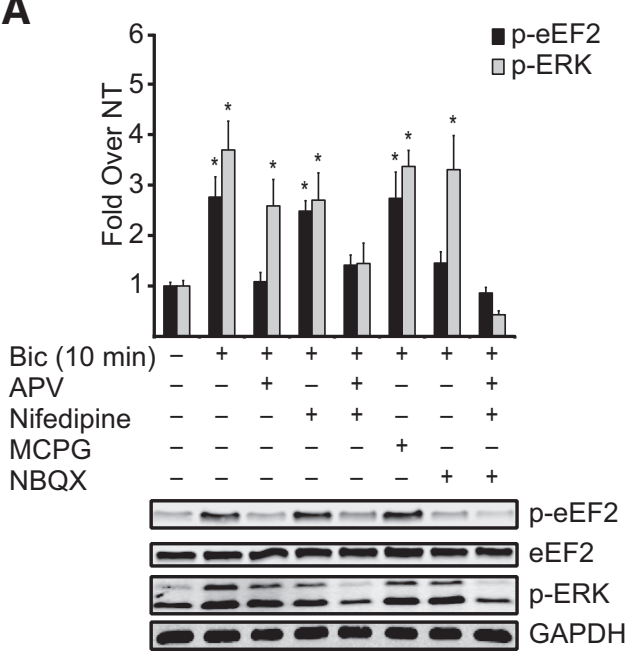

B

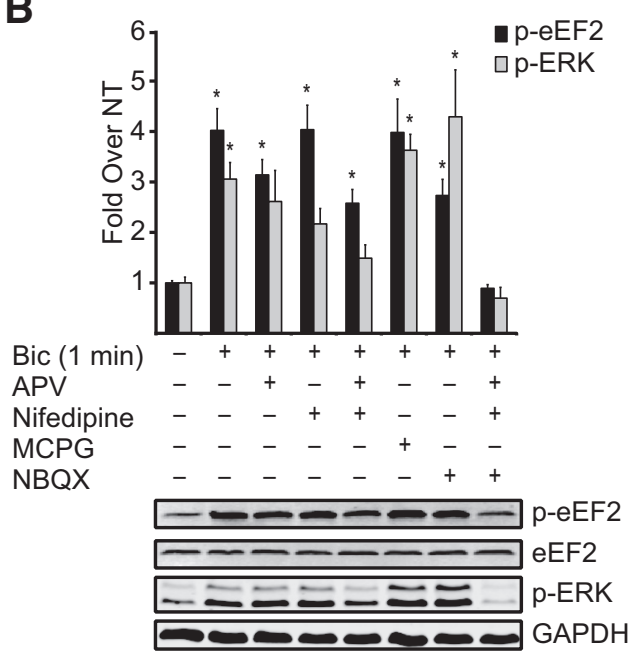

C

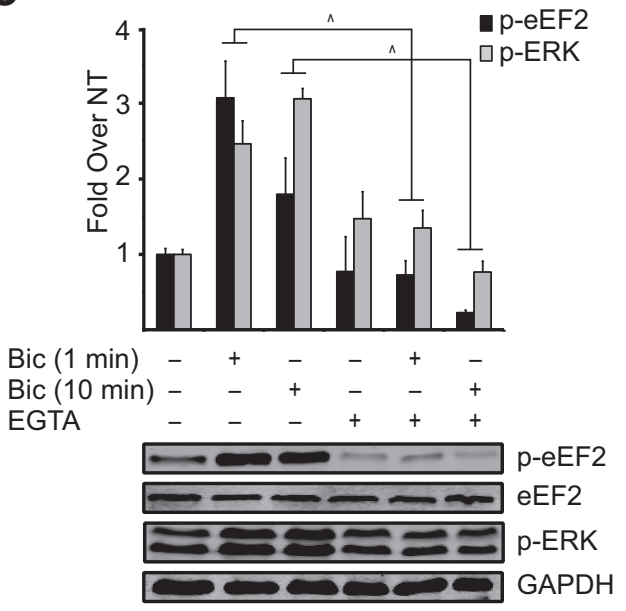

Figure 2. Elevated synaptic activity increased eEF2 phosphorylation via ionotropic receptors. $A, B$, The effects of pretreating neurons with receptor inhibitors before bicuculline (Bic) stimulation for $10(\boldsymbol{A})$ or $1(\boldsymbol{B})$ min on p-eEF2 and p-ERK with representative Western blots below the graphs. One-way ANOVAs revealed effects of treatment at both $10 \mathrm{~min}$ (p-eEF2, $F_{(7,34)}=3.5, p<0.001 ; p$-ERK, $\left.F_{(7,34)}=7.4, p<0.001 ; n=4-7\right)$ and 1 min $\left(p-e E F 2, F_{(7,41)}=9.6\right.$, $p<0.001 ; p$-ERK, $\left.F_{(7,41)}=8.7, p<0.001 ; n=4-8\right)$. C, The effect of administering EGTA immediately before bicuculline stimulation on p-eEF2 and $p$-ERK with representative Western blots shown below. A $3 \times 2$ (bicuculline $\times$ EGTA) ANOVA revealed a main effect of EGTA $\left(p\right.$-eEF2, $F_{(1,14)}=42.9, p<0.001 ; p$-ERK, $\left.F_{(1,14)}=50.4, p<0.001\right)$ and an interaction between 1 min of bicuculline administration and EGTA ( $p$-eEF2, $F_{(1,14)}=12.6, p=0.003$; bicuculline-induced increase in ERK phosphorylation (Fig. 3B). Furthermore, chelating extracellular calcium via EGTA administration during the last $10 \mathrm{~min}$ of a $60 \mathrm{~min}$ application of bicuculline also reversed the increase in ERK phosphorylation (Fig. 3C). These data suggest that functionally elevated levels of calcium are present after $60 \mathrm{~min}$ of bicuculline administration and that the decrease in eEF2 phosphorylation at this time point is most likely attributable to an active inhibition of eEF2K activity by other signaling pathways and not a decrease in intracellular $\mathrm{Ca}^{2+}$.

Both the mTORC1 and MEK/ERK pathways are known to be negative regulators of eEF2K activity (Wang et al., 2001; Carroll et al., 2004; Inamura et al., 2005), and both pathways are stimulated in response to bicuculline administration in cortical neurons (Fig. 1). To determine whether these signaling pathways are involved in returning eEF2K activity to baseline levels during prolonged bicuculline administration, either an MEK inhibitor (AZD6244) or an mTORC1 inhibitor (rapamycin) was administered before 20 or $60 \mathrm{~min}$ of bicuculline administration. Inhibition of either mTORC1 or MEK/ERK prevented the decrease in eEF2 phosphorylation after $60 \mathrm{~min}$ of bicuculline-stimulated synaptic activity (Fig. 3D). Furthermore, administration of AZD6244 alone resulted in a trend toward an increase in eEF2 phosphorylation, whereas rapamycin alone was without effect. This suggests that, at both basal and elevated levels of synaptic activity, the MEK/ERK pathway maintains tight regulation of eEF2K, whereas the mTORC1 pathway is only important during prolonged synaptic activity in cortical neurons. We also examined the regulation of $\mathrm{S} 6$ and ERK phosphorylation in this experiment and found that, although rapamycin had no effect on ERK phosphorylation (Fig. 3E), AZD6244 administration resulted in a modest inhibition of $\mathrm{S} 6$ phosphorylation (Fig. $3 F$ ). This suggests that the mTORC1 pathway is downstream of the MEK/ERK pathway in cortical neurons, as has been reported previously in some cell types, such as hippocampal neurons, but not others (Kelleher et al., 2004; Roux et al., 2004; Ma et al., 2005; Fonseca et al., 2011).

\section{Development of a kinetic model for the regulation of eEF2K}

To test the hypothesis that $\mathrm{Ca}^{2+}$-coordinated MEK/ERK, mTORC1, and eEF2K regulation is sufficient to describe the observed eEF2K dynamics, we developed a kinetic model (Fig. 4). We restricted our initial model to major regulatory components with the aim of determining whether their known interactions would be sufficient to reproduce the empirical observations. We built the ordinary differential equation model based on current knowledge about the structure of MEK/ERK, MTORC1, and eEF2K interactions and their regulation by intracellular $\mathrm{Ca}^{2+}$ influx (Fig. 4, colored squares). The initial model had three modules: (1) an MEK/ERK module (Fig. 4, red), the core of which was adopted from Hornberg et al. (2005) as presented in the BioModels Database; the model of Hornberg et al. was modified by the inclusion of PP2A as an explicit enzyme for MEK dephosphorylation (Alessi et al., 1995) and receptor activation at the top of the cascade, which was modeled as direct $\mathrm{Ca}^{2+} / \mathrm{CaM}$-dependent Ras protein activation by the GDP/GTP exchange factor RasGRP (Caloca et al., 2003); (2) a module for mTORC1/S6K1 phosphorylation based on the mechanism described by Lenz and Avruch

p-ERK, $F_{(1,14)}=14.0, p=0.002$ ) and 10 min of bicuculline administration and EGTA (p-eEF2, $\left.F_{(1,14)}=5.2, p=0.039 ; p-E R K, F_{(1,14)}=41.7, p<0.001\right) ; n=2-4$. Data represent mean \pm SEM; ${ }^{*} p<0.05$ compared with untreated neurons (NT), $\hat{p}<0.05$. 
A

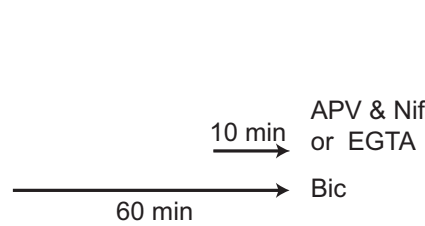

D

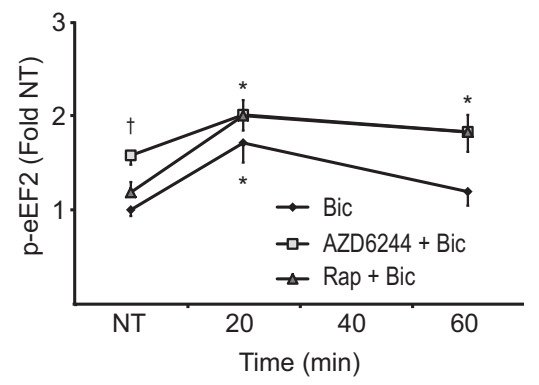

$\mathbf{F}$

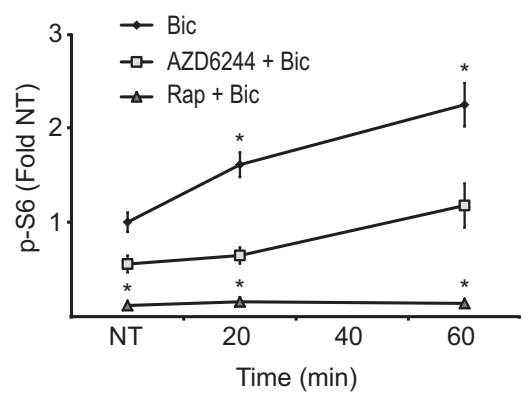

B

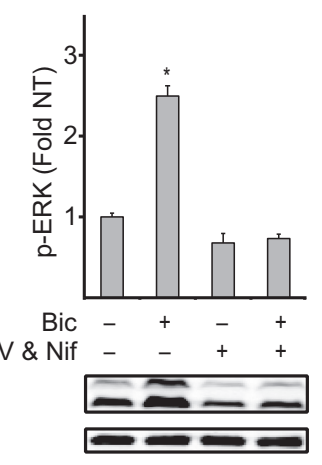

C

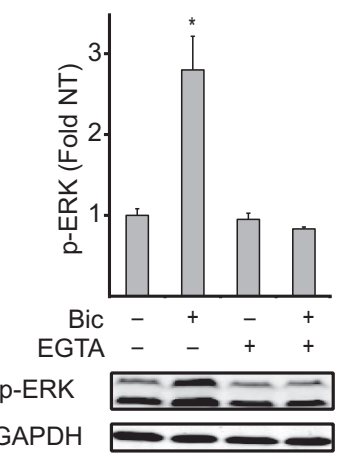

\section{E}

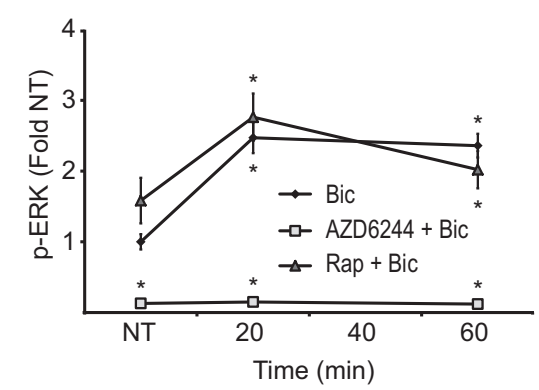

G

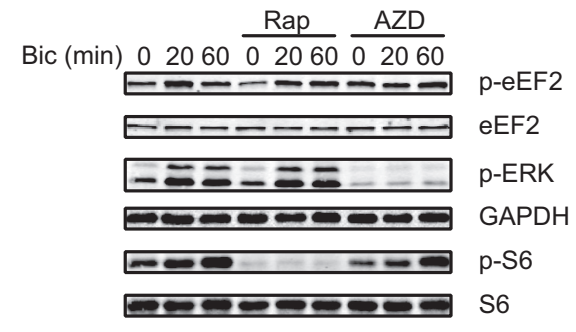

al., 2005; Lenz and Avruch, 2005; Gulati et al., 2008). (2) p-ERK also stimulates the mTORC1 pathway, resulting in phosphorylation of S6K1 (based on Fig. 4C and Kelleher et al., 2004; Fonseca et al., 2011). (3) Dephosphorylation in the model is regulated mainly via $\mathrm{PP} 2 \mathrm{~A}$, which in turn is a substrate for inhibition by activated mTORC1 (Narayanan et al., 2007). (4) eEF2 $\mathrm{K}$ is activated by an increase in intracellular $\mathrm{Ca}^{2+}$ via its interaction with $\mathrm{Ca}^{2+} / \mathrm{CaM}$ (Ryazanov et al., 1988). (5) In the model, eEF2K is phosphorylated by ERK and S6K1, which leads to an inactivation of $\mathrm{Ca}^{2+} / \mathrm{CaM}-$ bound $\mathrm{eEF} 2 \mathrm{~K}$ (Wang et al., 2001). We also considered an alternative mechanism for the inactivation of eEF2K by ERK and S6K1 in which phosphorylation of eEF2K by these kinases results in decreased affinity of eEF2K for $\mathrm{Ca}^{2+} / \mathrm{CaM}$. However, the model was unable to reproduce the experimental data under this assumption, so we built the model assuming that phosphorylation of eEF2K results in an inactivation of the kinase with no effect on $\mathrm{Ca}^{2+} / \mathrm{CaM}$ binding. Several simplifying assumptions were made for modeling purposes. As a result, known biochemical interactions were not explicitly modeled but are subsumed in specific parameters. For example, the activation of $\mathrm{p} 90^{\mathrm{RSK}}$ by ERK that then directly phosphorylates eEF2K (Wang et al., 2001) is not explicitly included. Rather, it is represented by parameters describing ERK/eEF2K interactions.

To directly test the hypothesis that the observed MEK/ERK and mTORC1 activation profiles would be sufficient to explain the dynamic nature of eEF2K regulation in neurons, the parameters for the ERK and mTORC1 modules were initially set by fitting to the empirical data (Fig. 5A). Only after these parameters were set was an attempt made at fitting the model to the eEF2 phosphorylation data. The model was fit to time series curves from five experiments [long- and shortterm bicuculline (Fig. 1) and bicuculline with and without inhibitors (Fig. 3)]. A combination of local and global optimization algorithms were used for the fitting

(2005) and Gulati et al. (2008), in which $\mathrm{Ca}^{2+} / \mathrm{CaM}$ formation results in mTORC1 activation (Fig. 4, brown); and (3) an eEF2K module in which all inputs and crosstalks converge to control the regulation of eEF2K-catalyzed eEF2 phosphorylation (Fig. 4, dark green).

To build the model, we assembled the modules in the following way. (1) Both p-ERK and p-S6K1 inhibit eEF2K in response to intracellular $\mathrm{Ca}^{2+}$ influx. p-ERK is a result of stimulation of the Ras/Raf/MEK pathway, and the phosphorylation of S6K1 is mediated by activation of mTORC1 by $\mathrm{Ca}^{2+} / \mathrm{CaM}$ (Hornberg et process (for details, see Materials and Methods).

The model successfully reproduced the behavior of ERK and S6 phosphorylation over the entire experimental time course and was mostly able to capture eEF2 phosphorylation dynamics (Fig. $5 B$ ). However, our initial model was unable to describe to the same level of accuracy the effects of inhibiting the MEK/ERK and mTORC1 pathways. Inclusion of differential binding of $\mathrm{Ca}^{2+}$ / CaM to different interacting partners based on the level of occupancy of CaM by $\mathrm{Ca}^{2+}$ (Faas et al., 2011; for details, see Materials and Methods) resulted in a better fit to the combined bicuculline 


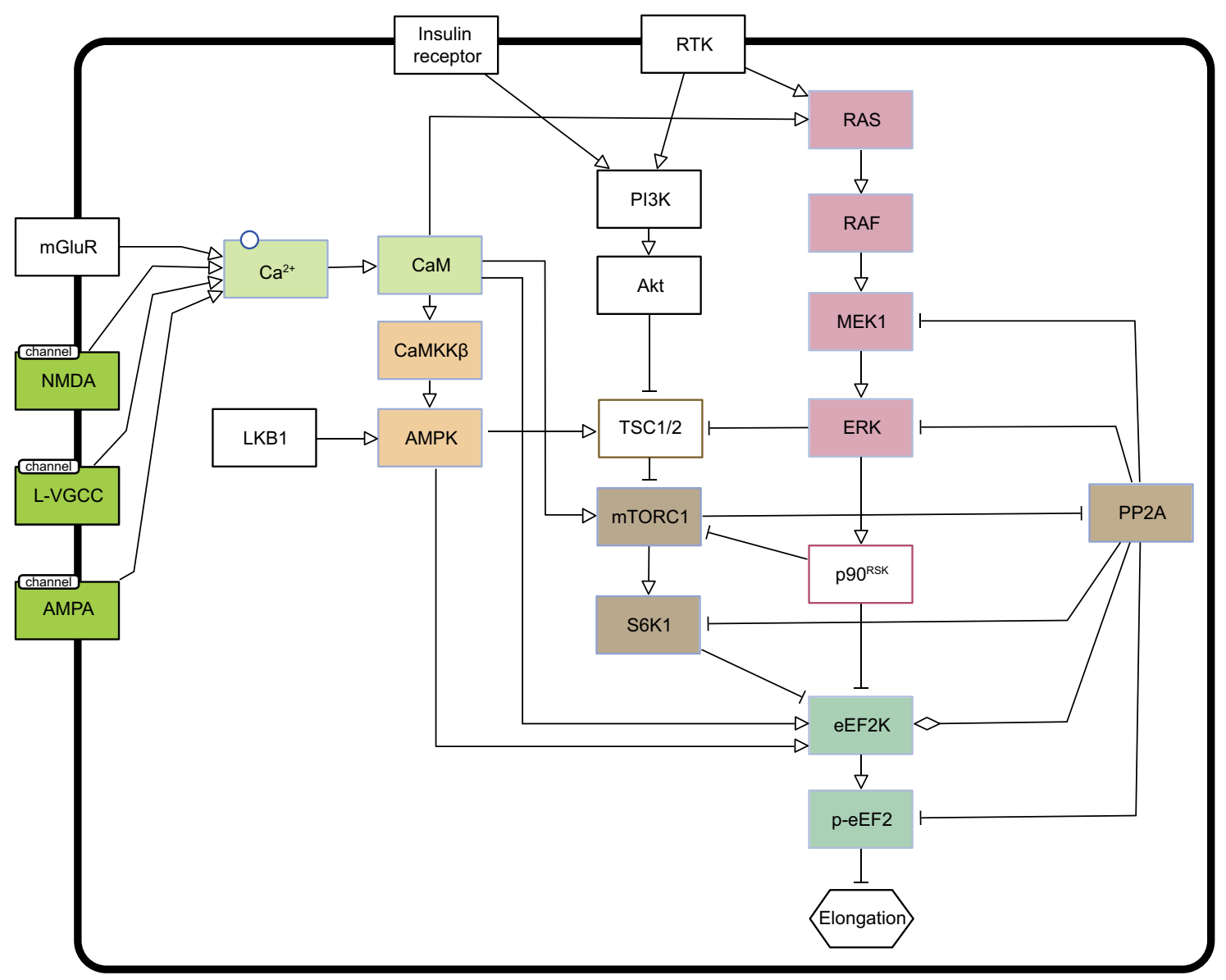

Figure 4. Depiction of various pathways that are known to contribute to eEF2K regulation in systems biology graphical notation (SBGN) activity flow format (Le Novère et al., 2009). Arrows represent activation, plungers represent inhibition, and diamonds represent modulation when both activation and inhibition are possible depending on other inputs. Filled boxes indicate

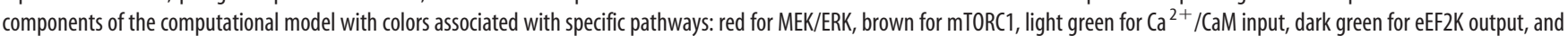
orange for AMPK. Colored framed boxes for TSC1/2 (mTORC1 pathway) and p90 ${ }^{\text {RSK }}$ (MEK/ERK pathway) correspond to components that are implied in the model although not represented by specific parameters. Black framed boxes correspond to pathway elements not explicitly considered in the model. LKB1, Liver kinase B1; PI3K, phosphatidylinositol 3-kinase; RTK, receptor tyrosine kinase; TSC1/2, tuberous sclerosis complex $1 / 2$.

and AZD6244 or rapamycin and reduced the value for a leastsquares fit cost function for p-ERK, p-S6, and p-eEF2 by $60 \%$ (Fig. 5C,D).

\section{Involvement of AMPK in the regulation of eEF2K}

Our computational model demonstrated that the combined activity of the MEK/ERK and mTORC1 pathways is sufficient to explain the short-term dynamics of eEF2K regulation in response to elevated synaptic activity (10-20 min after bicuculline administration (Fig. 5B). However, the longer-term dynamics (i.e., at 40-60 min) were not fully captured, because the model predicted significantly lower levels of eEF2 phosphorylation than was observed experimentally (Fig. 5B). Intuitively, this could be interpreted as though an additional positive regulator of eEF2K, with sustained activity up to $60 \mathrm{~min}$, was lacking from the model. Thus, we considered two known positive regulators of eEF2K: (1) protein kinase A (PKA) and (2) AMPK (Redpath and Proud, 1993; Horman et al., 2003; Browne et al., 2004). Previous work has found that cAMP, a key upstream effector of PKA, does not increase in response to bicuculline, membrane depolarization, or glutamate application in neurons (Pokorska et al., 2003), whereas AMPK is known to be activated by CaMKK $\beta$ (Hawley et al., 2005; Woods et al., 2005). Therefore, we focused on AMPK as the missing positive regulator.
The model was extended to include a fourth module that describes AMPK activation in response to elevated intracellular $\mathrm{Ca}^{2+}$ that results in additional activation of eEF2K (Fig. 1, orange). In addition, we also incorporated the negative regulation of mTORC1 by AMPK (Inoki et al., 2003; Kimura et al., 2003). The now updated model was again fitted to the same set of experimental data as before, but this time only the AMPK and eEF2related parameters were free to change while the rest of the parameters remained constrained. As expected, the addition of AMPK in the model substantially improved model performance. The four-pathway model resulted in an excellent fit of eEF2 phosphorylation after $40-60 \mathrm{~min}$ of bicuculline stimulation without loss of fitting ERK and S6 phosphorylation (Fig. 6A).

We tested experimentally whether bicuculline-induced synaptic activity results in increased AMPK activity via $\mathrm{Ca}^{2+}$ influx and whether it influences eEF2K activity. Bicuculline administration resulted in a rapid and sustained increase in the phosphorylation of both AMPK (T172) and ACC, a well defined AMPK substrate (Fig. $6 B-D$ ). Furthermore, the observed activation profile of AMPK was qualitatively very similar to that predicted by the mathematical model (Fig. 6E). To determine whether AMPK activation alone is sufficient to stimulate eEF2K, we used A769662, a selective activator of AMPK (Cool et al., 2006; Guigas et al., 2009). A769662 resulted in an increase in both ACC and 
A

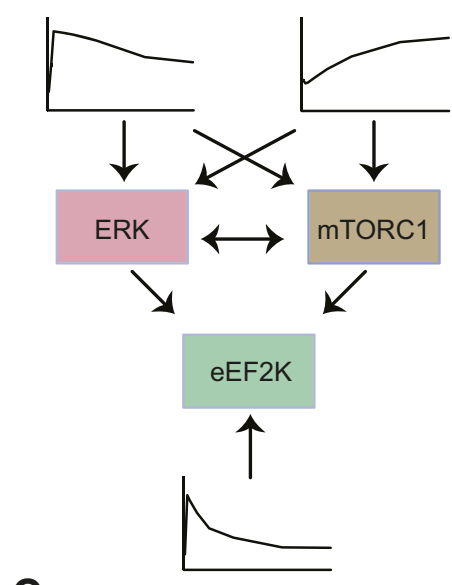

C

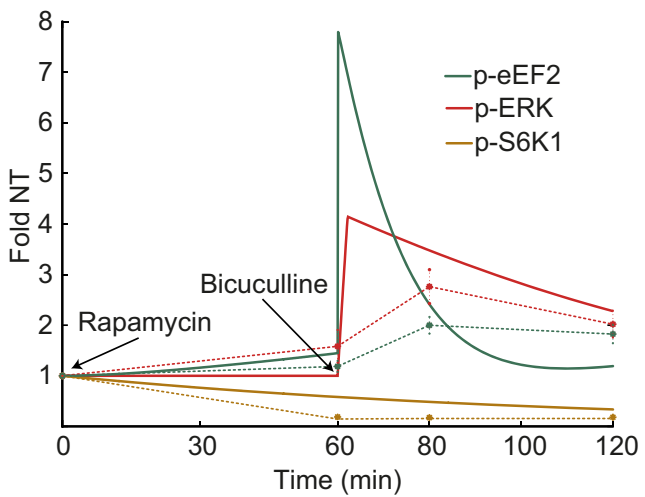

B

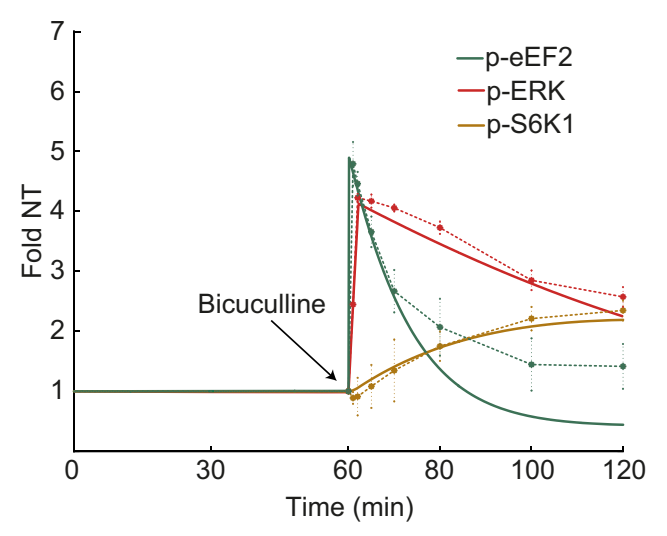

D

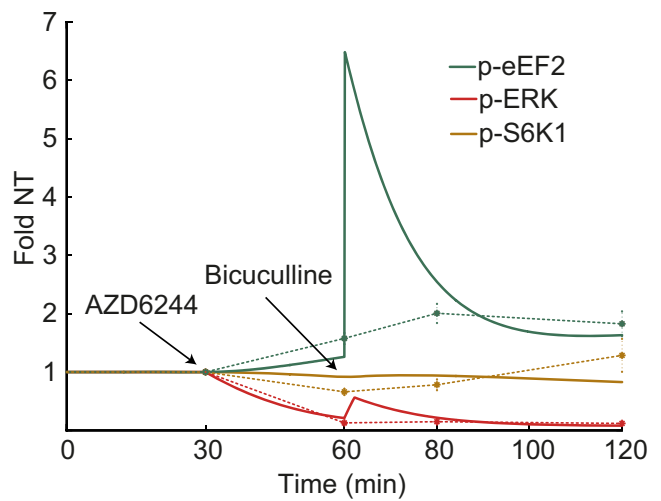

Figure 5. Simulations of experimental data using kinetic modeling. Solid lines correspond to the outcomes of modeling, and dashed lines correspond to experimental data. Line colors correspond to respective modules outlined in Figure 4 . $\boldsymbol{A}$, Workflow of the model development. ERK and mTORC1 modules were initially fit to experimental data, after which the eEF2K module was then attempted to be fit to the eEF2 phosphorylation data. $\boldsymbol{B}$, Simulation of bicuculline application along with experimental data from Figure 1. Bicuculline is added at 60 min (arrow). $\boldsymbol{C}$, Simulation of rapamycin treatment before bicuculline administration (data from Fig. 4). Rapamycin is added at time 0 , and bicuculline is added at 60 min (arrows). $\boldsymbol{D}$, Simulation of AZD6244 treatment before bicuculline administration (data from Fig. 4). AZD6244 was added at 30 min and bicuculline at 60 min (arrows). NT, Not treated.

eEF2 phosphorylation (Fig. $6 F, G$ ). A769662 did not alter AMPK phosphorylation, consistent with A769662 being an allosteric modulator of AMPK (Göransson et al., 2007; Sanders et al., 2007), but did result in a decrease in S6 phosphorylation, consistent with AMPK negatively regulating mTORC1 (Inoki et al., 2003; Kimura et al., 2003). However, it is unlikely that the effect of A769662 on mTORC1 is responsible for the increase in eEF2 phosphorylation given that rapamycin administration alone, which results in a greater decrease in S6 phosphorylation than A769662, did not affect eEF2 phosphorylation (Fig. $4 B)$. Finally, APV and nifedipine were applied during the last $10 \mathrm{~min}$ of a $60 \mathrm{~min}$ period of bicuculline stimulation (Fig. $3 \mathrm{~A}$ ). This reversed the synaptic activity-induced increase in both AMPK and ACC phosphorylation (Fig. $6 \mathrm{H}-\mathrm{J}$ ), indicating that AMPK is regulated by $\mathrm{Ca}^{2+}$ influx through NMDARs and $\mathrm{L}-\mathrm{VGCC}$ in response to elevated synaptic activity in neurons.

\section{Comparison of models with and without AMPK}

To further validate the inclusion of AMPK into the model, we sought a means to directly compare predictions from models with and without AMPK. In particular, we were interested in predictions based on conditions in which experimental data had not been obtained previously and used for model fitting. We noted that our initial model without AMPK predicted a higher level of eEF2 phosphorylation after 1 min of bicuculline admin- istration in the presence of either rapamycin or AZD6244 compared with bicuculline alone (Fig. 5, compare $B$ with $C, D$ ). We then generated a prediction under the same conditions using the model that includes AMPK. The inclusion of AMPK resulted in a substantially lower prediction for the levels of bicucullineinduced eEF2 phosphorylation in the presence of either rapamycin or AZD6244 (Fig. 7A). We tested these two contrasting predictions experimentally and found that $1 \mathrm{~min}$ of bicuculline administration in the presence of either rapamycin or AZD6244 results in only a very modest increase in eEF2 phosphorylation over bicuculline alone (Fig. $7 B$ ). Furthermore, a comparison of the predictions of the two models (with and without AMPK) with the experimental data indicated that the model that includes AMPK results in a much closer match to the empirical findings (Fig. 7C).

To determine why the model that included AMPK resulted in a lower relative increase of p-eEF2 after bicuculline administration in the presence of AZD6244 or rapamycin than the model that did not include AMPK, we more closely examined the values for p-eEF2 during the steady state and in response to bicuculline in the two models. We found that the discrepancy between the two models was primarily attributable to differences in baseline levels of p-eEF2. The model that included AMPK had higher basal concentrations of p-eEF2 than the model without AMPK ( 4.0 vs $0.7 \mathrm{nM}$ ). After $1 \mathrm{~min}$ of bicuculline administration in the 
A

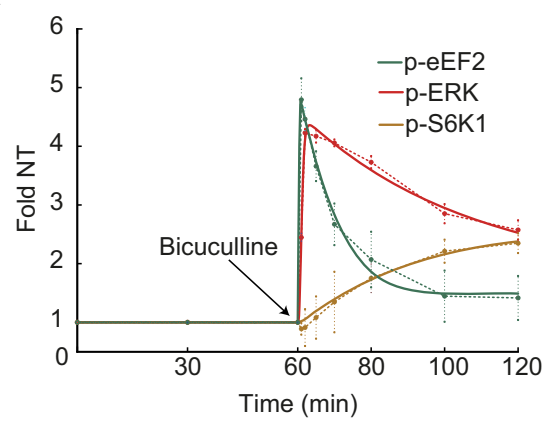

B
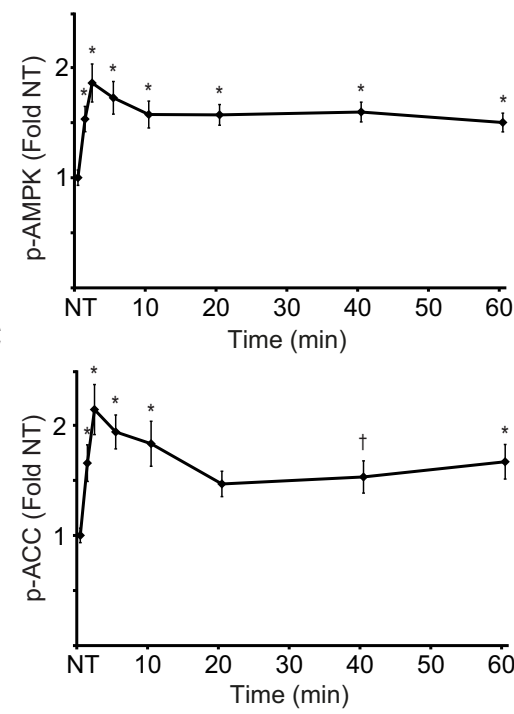

D

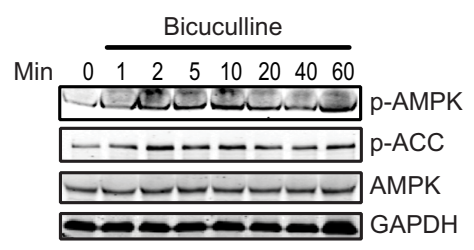

E

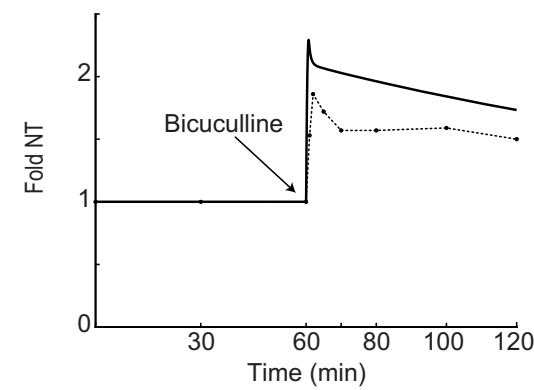

$\mathbf{F}$
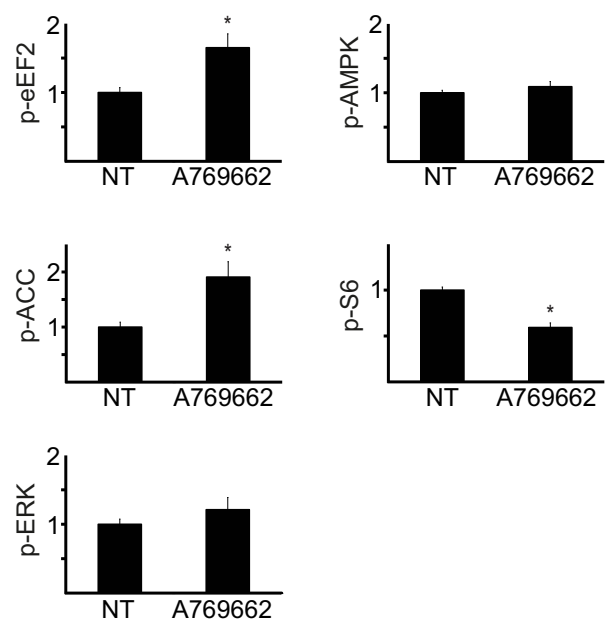

G

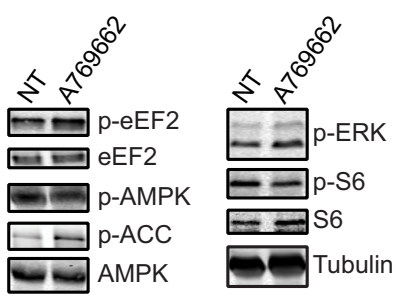

H I

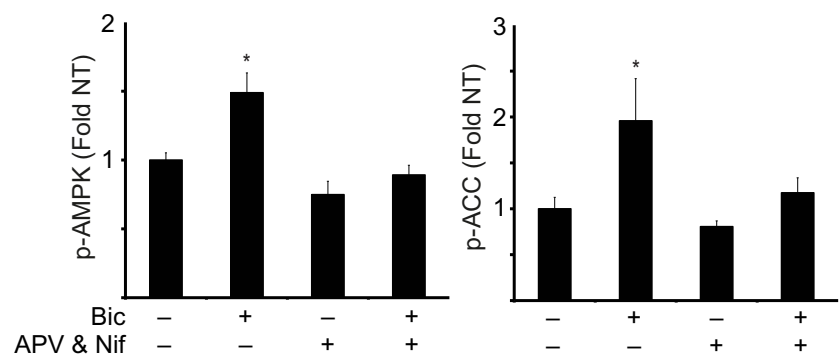

$J$

Bic -+-+

APV \& Nif $-\quad++$ p-AMPK

D-ACC

AMPK

GAPDH

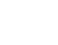

Figure 6. Modeling and experimental evidence implicate AMPK regulation of eEF2K in cortical neurons. $\boldsymbol{A}$, Simulation of bicuculline administration in cortical neurons (solid lines) compared with experimental data (dashed lines) with the inclusion of AMPK in the kinetic model. $B, C$, The effect of continuous bicuculline administration on p-AMPK (T172) and p-ACC. One-way ANOVAs revealed effects of stimulation on $\mathrm{p}-\mathrm{AMPK}\left(F_{(7,61)}=4.7, p<0.001\right)$ and $\mathrm{p}-\mathrm{ACC}\left(F_{(7,62)}=4.7, p<0.001\right) ; n=8-9 . \boldsymbol{D}, \mathrm{Representative} \mathrm{Western} \mathrm{blots} \mathrm{for} \mathrm{data} \mathrm{presented}$ in $\boldsymbol{B}$ and $\boldsymbol{C}$. $\boldsymbol{E}$, Comparison of model prediction of p-AMPK (solid line) with experimental data (dashed line). $\boldsymbol{F}$, The effect of $100 \mu \mathrm{M}$ A769662 administered for 60 min to cortical neurons on p-eEF2, p-AMPK, p-ACC, p-S6 (S240/244), and p-ERK. A769662 resulted in an increase in p-eEF2 $\left(t_{(10)}=3.0, p=0.012\right)$ and p-ACC $\left(t_{(10)}=3.1, p=0.011\right)$ and a decrease in p-S6 $\left(t_{(10)}=6.8, p<0.001\right)$ and had no effect on $p$-AMPK $\left(t_{(10)}=1.1, p=0.31\right)$ or $p$-ERK $\left(t_{(10)}=1.1, p=0.30\right) ; \boldsymbol{n}=6$. $\boldsymbol{G}$, Representative Western blots for data presented in $\boldsymbol{F}$. $\boldsymbol{H}, \boldsymbol{I}$, The effects of administering APV and nifedipine (Nif) during the last 10 min of a 60 min bicuculline (Bic) stimulation (Fig. $3 A$ ) on $p$-AMPK and $p$-ACC. The $2 \times 2$ ANOVAs revealed a main effect of bicuculline treatment on both $p-A M P K\left(F_{(1,12)}=10.6, p=0.007\right)$ and $p-A C C\left(F_{(1,12)}=6.9, p=0.02\right)$, a main effect of APV and nifedipine on $p-A M P K\left(F_{(1,12)}=19.1, p=0.001\right)$, a trend toward an effect on $\mathrm{p}-\mathrm{ACC}\left(F_{(1,12)}=3.7, p=0.077\right)$, a trend toward an interaction on $\mathrm{p}-\mathrm{AMPK}\left(F_{(1,12)}=3.2, p=0.099\right)$, and no interaction for $p-A C C\left(F_{(1,12)}=1.4, p=0.27\right)$; $n=4$. $\boldsymbol{J}$, Representative Western blots for data presented in $\boldsymbol{H}$ and $\boldsymbol{I}$. Data represent mean $\pm \mathrm{SEM} ;{ }^{*} p<0.05,{ }^{\dagger} p=0.10$ compared with untreated neurons (NT). 
A

\begin{tabular}{rcc} 
& \multicolumn{2}{c}{ p-eEF2 } \\
& $\begin{array}{c}\text { Model 1 } \\
\text { (- AMPK) }\end{array}$ & $\begin{array}{c}\text { Model 2 } \\
\text { (+AMPK) }\end{array}$ \\
\hline Bic (1 min) & 4.72 & 4.76 \\
AZD6244 + Bic (1 min) & 6.62 & 5.11 \\
Rapamycin + Bic (1 min) & 7.89 & 4.95
\end{tabular}

C

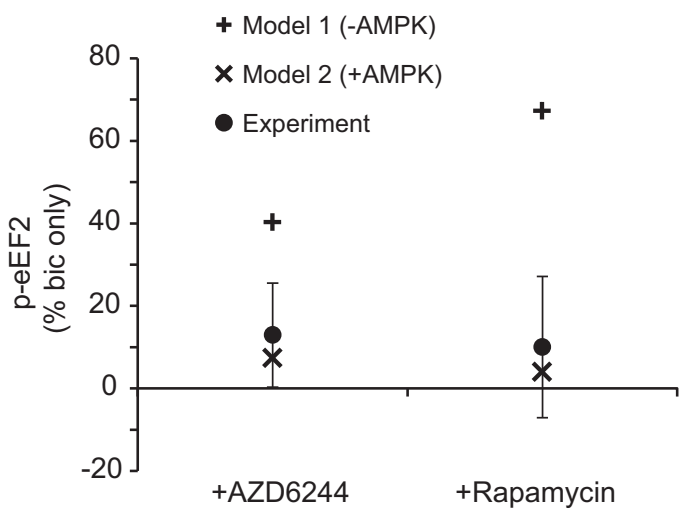

B

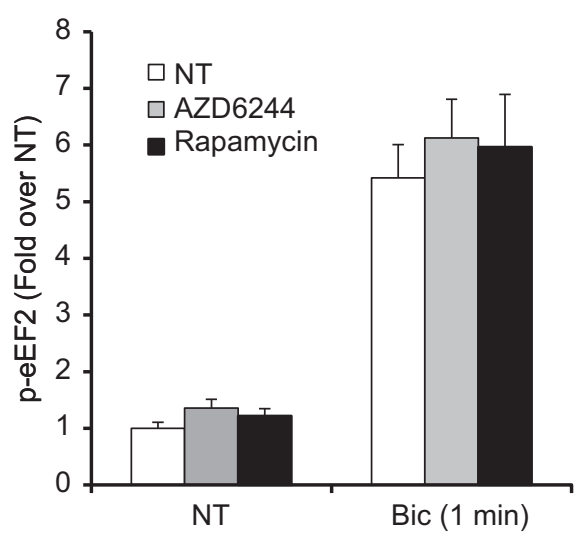

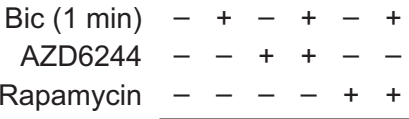

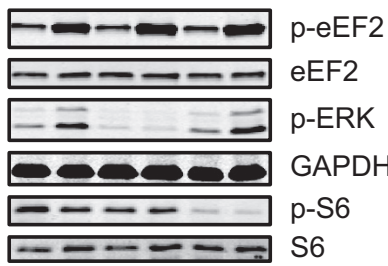

Figure 7. Including AMPK in the model results in a more accurate prediction of short-term bicuculline-induced eEF2 phosphorylation in the presence of rapamycin or AZD6244. $\boldsymbol{A}$, Comparison of model predictions for levels of p-eEF2 after 1 min of bicuculline (Bic) administration in the presence of AZD6244 or rapamycin. Model 1 corresponds to the initial model (Fig. 5), and model 2 corresponds to the model with the inclusion of AMPK (Fig. 6). B, The effect of stimulating neurons with bicuculline for 1 min in the presence or absence of AZD6244 or rapamycin on p-eEF2 with representative Western blots shown below. A $2 \times 3$ (bicuculline $\times$ inhibitor) ANOVA revealed a main effect of bicuculline $\left(F_{(1,65)}=115, p<0.001\right)$ but no main effect of inhibitor $\left(F_{(2,65)}<1, p=\right.$ $0.59)$ or an interaction $\left(F_{(2,65)}<1, p=0.94\right) ; n=11-12$. Data represent mean \pm SEM; ${ }^{*} p<0.05$ compared with untreated neurons (NT). $C$, Comparison of experimental results and the predictions from the model that lacks AMPK (model 1; Fig. 5) and one that includes AMPK (model 2; Fig. 6). Data are presented as percentage change relative to predictions or experiment in which bicuculline was administered for $1 \mathrm{~min}$. Experimental data represent mean $\pm \mathrm{SEM}$.

presence of, for example, rapamycin, the model with AMPK predicted an increase in p-eEF 2 to a concentration of $20 \mathrm{nM}$, whereas without AMPK the model predicted $5.5 \mathrm{~nm}$. Thus, as would be expected, the model including AMPK resulted in higher absolute concentrations of p-eEF2 but lower relative increases after bicuculline stimulation in the presence of AZD6244 or rapamycin (Fig. 7C).

\section{Sensitivity analysis}

We performed sensitivity analysis of our final model to determine which pathways made the greatest contribution to the regulation of p-eEF2 (see Notes). We found that, although both the MEK/ ERK and mTORC1 pathways significantly contribute to the levels of p-eEF2, the parameters with the largest influence arose from the AMPK pathway. This is consistent with our experimental data in which we find that inhibiting the MEK/ERK or mTORC1 pathways in the absence of bicuculline has modest effects on p-eEF2 (Fig. 3D), whereas activating AMPK alone is sufficient to increase p-eEF2 (Fig. 6F).

\section{Discussion}

We find that synaptic activity-induced eEF2K regulation in primary neurons is both rapid and dynamic. The regulation of eEF2K depends on $\mathrm{Ca}^{2+}$ influx through ion channels/receptors and the $\mathrm{Ca}^{2+}$ coordinated regulation of various cell signaling pathways. We used a data-driven mechanistic model to test the hypothesis that $\mathrm{Ca}^{2+}$-coordinated mTORC1 and MEK/ERK reg- ulation could explain the observed eEF2K dynamics. Initial discrepancies and additional iterations between modeling and experimental work found that AMPK is also a key determinant of synaptic activity-induced eEF2K signaling in neurons.

The use of primary neuronal cell cultures to examine the intricacies of cell signaling in the present study has both strengths and weaknesses. Whereas the vast majority of biochemical studies of eEF2K, mTORC1, MEK/ERK, and AMPK are performed in cancer cell lines with stimuli that may have only tangential relevance to neuronal signaling, primary neuronal cultures provide direct access to an untransformed, mostly homogenous population of neurons and the use of neuronally relevant stimuli. However, given that the brain is actually a heterogeneous mixture of many cell types and contains well defined circuitry that is unlike the stochastic connectivity of neurons in culture, care must be taken when interpreting results from neuronal cultures in the context of whole-brain function. Nonetheless, the findings from the present study may shed light on some of the complex findings regarding the regulation of eEF2K in the brain and neurons. For example, after the acquisition of a conditioned taste aversion learning task in mice, there is an increase in eEF2 phosphorylation in the gustatory cortex (Belelovsky et al., 2005; Gildish et al., 2012). In contrast, after the acquisition of contextual fear conditioning, there is a decrease in eEF2 phosphorylation in the hippocampus (Im et al., 2009). In addition, differential compartmental regulation of eEF2K has been found in Aplysia sensory neurons in 
which 5-HT application results in a decrease in eEF2 phosphorylation in neurites but an increase at the soma (Carroll et al., 2004; Weatherill et al., 2011), and the application of BDNF to primary neurons results in a decrease in eEF2 phosphorylation (Takei et al., 2009) but BDNF applied to the dentate gyrus in vivo results in increased eEF2 phosphorylation (Kanhema et al., 2006). Finally, eEF2K activity at the synapse has been found to decrease after evoked synaptic transmissions but to increase as a result of spontaneous transmission (Sutton et al., 2007). Our finding that considering only mTORC1 and MEK/ERK signaling was insufficient to describe eEF2K dynamics suggests a possible explanation for many of these disparate findings. Indeed, most studies examining the regulation of eEF2K in neuronal preparations have focused on the role of the mTORC1 signaling pathway (Carroll et al., 2004; Inamura et al., 2005; Weatherill et al., 2011) with scant attention paid to the MEK/ERK pathway (Belelovsky et al., 2005; Kanhema et al., 2006) and none to AMPK. Although our findings make use of whole-cell lysates, in which $\sim 95 \%$ is thought to be nonsynaptic in origin (Chang et al., 2012), our data suggest that an examination of all three of these pathways in the various preparations is required to adequately assess eEF2K dynamics. Doing so will likely help explain the apparent differences in eEF2K regulation across different compartments, brain regions, and neuronal preparations.

The rapid regulation of eEF2K by elevated synaptic activity that we have examined and modeled provides a framework for a deeper understanding of some of the mechanisms involved in a variety of synaptic activity-related phenomena, such as learning and memory, synaptic plasticity, and neuroprotection. The rapid bicuculline-induced increase in eEF2K activity in cortical neurons in the present study was found to depend on NMDA and AMPA-type GluRs, mechanisms known to be necessary for both memory acquisition and the induction of long-term potentiation (Abel and Lattal, 2001). Furthermore, the involvement of the MEK/ERK and mTORC1 pathways in learning and synaptic plasticity are well documented (Kelleher et al., 2004; Sweatt, 2004; Costa-Mattioli et al., 2009), and, more recently, the AMPK pathway has been implicated in both synaptic plasticity (Potter et al., 2010) and learning (Dagon et al., 2005; Dash et al., 2006). This suggests that that eEF2K may be an important downstream effector of these pathways in the context of learning. The administration of bicuculline to primary neurons for considerably longer periods than examined here also results in a modest mGluR-dependent increase in eEF2 phosphorylation (Verpelli et al., 2010), a mechanism important for the induction of long-term depression (Park et al., 2008). This longer-term bicuculline administration more closely models homeostatic plasticity (Desai, 2003), thereby suggesting that eEF2K may be involved in multiple forms of plasticity. Finally, bicuculline-induced synaptic activity is also known to be neuroprotective (Hardingham et al., 2002; Lee et al., 2005). AMPK presents an intriguing target for understanding bicuculline-induced neuroprotection given that it is not only stimulated by $\mathrm{Ca}^{2+}$ but is also a key sensor of energy/ATP in the cell that makes significant contributions to phenomena such as ischemia (Ronnett et al., 2009). Given that eEF2K regulates one of the most energy-consuming processes in cells and is important for cell survival in non-neuronal cells (Terai et al., 2005; Leprivier et al., 2013), there may be interesting and complex relationships between $\mathrm{Ca}^{2+}$ influx, ATP, AMPK, and eEF2K in regulating neuroprotection that requires additional study.
The cell signaling network in neurons is large, complex, and incompletely understood. Although formal mathematical models are a powerful approach for testing specific hypotheses about whether a given set of molecular interactions is sufficient to explain empirical findings, such models require a delicate balance between including too many and too few parameters (Di Ventura et al., 2006). In addition, there is little information regarding the specific concentrations of proteins and dissociation constants for model development, making it imperative to minimize the parameter space explored while simultaneously ensuring that the appropriate network of interactions is maintained. Inclusion of more parameters than necessary to describe a particular network structure can lead to overfitting and a loss of biological plausibility. In the present study, we circumvented some of these issues by focusing on pathways in which we had high-quality data and carefully designed our model to test a specific hypothesis, i.e., can we explain eEF2K dynamics given the activation profiles of the mTORC1 and MEK/ERK pathways? By initially fitting the mTORC1 and MEK/ERK modules of the model to the p-S6 and p-ERK data and only then attempting to fit the eEF2K module to the p-eEF2 data (Fig. $5 \mathrm{~A}$ ), we directly tested this hypothesis. Although the initial model only incompletely fit the eEF2 phosphorylation data, it did yield a strikingly accurate prediction of AMPK activation in response to bicuculline (Fig. 6E). This approach also resulted in realistic estimates of $\left[\mathrm{Ca}^{2+}\right]$. Fitting $\mathrm{Ca}^{2+}$-related parameters to the experimental data resulted in a value for resting-state $\left[\mathrm{Ca}^{2+}\right]$ of $59 \mathrm{nM}$ and a bicuculline-induced peak of $54 \mu \mathrm{M}$, both of which are in line with empirical observations (Petrozzino et al., 1995; Maravall et al., 2000). Furthermore, the model including AMPK accurately predicted eEF2 phosphorylation levels under conditions in which the model was never fit to experimental data (Fig. 7). Together, these findings support the contention that our model accurately captures the major features of the signaling dynamics involved in eEF2K regulation.

Our ODE model clearly captures a high proportion of eEF2K regulatory dynamics with demonstrated predictive validity, making it useful for additional hypothesis generation and experimental testing. For example, whereas the inhibitory inputs into eEF2K from the MEK/ERK and mTORC1 pathways were modeled as phosphorylation events that inactivate eEF2K, the details of this mechanism require additional exploration. We tested, in silico, the two most obvious and simple mechanisms of inactivation and found that phosphorylation-induced inhibition of active $\mathrm{Ca}^{2+}$ / CaM-bound eEF2K fits the experimental data better than a mechanism in which phosphorylation of eEF2K prevents its binding to $\mathrm{Ca}^{2+} / \mathrm{CaM}$. Nonetheless, there are additional elements that should be considered for the future development of a more complex model. For example, eEF2K has been reported recently to be controlled by cyclin-dependent kinase-2 (Hizli et al., 2013) and undergoes significant regulatory autophosphorylation (Pyr Dit Ruys et al., 2012; Tavares et al., 2012). Additional iterations between modeling and experiments would determine what role these events and others may play in eEF2K dynamics, leading to a more sophisticated and nuanced understanding of the mechanisms underlying eEF2K regulation in various conditions.

Taken together, the experimental data and modeling in the present study provide the first in-depth examination of the dynamics of eEF2K regulation. Although previous work studying eEF2K in neurons focused primarily on its regulation by 
mTORC1 with some consideration of MEK/ERK, our combined data and modeling suggest that such an approach is inadequate for understanding eEF2K regulatory dynamics: AMPK also makes a substantial contribution of eEF2K regulation in both the short and intermediate terms. Continuing refinement of the model and better understanding of the control of eEF2K will provide insights into diverse eEF2K-regulated processes, such as learning and memory, ischemia, and cell survival (Gal-Ben-Ari et al., 2012; Romero-Ruiz et al., 2012; Leprivier et al., 2013).

\section{Notes}

Supplemental material for this article is available at http://www.inf.ed.ac. uk/ jda/eEF2k. It includes the following: (1) a supplemental file describing the model in greater detail, including all equations in the model, a detailed process diagram of model, and details of the sensitivity analysis and figures; (2) a table of the model parameters; and (3) the model in SBML format. This material has not been peer reviewed.

\section{References}

Abel T, Lattal KM (2001) Molecular mechanisms of memory acquisition, consolidation and retrieval. Curr Opin Neurobiol 11:180-187. CrossRef Medline

Alessi DR, Gomez N, Moorhead G, Lewis T, Keyse SM, Cohen P (1995) Inactivation of $\mathrm{p} 42 \mathrm{MAP}$ kinase by protein phosphatase $2 \mathrm{~A}$ and a protein tyrosine phosphatase, but not CL100, in various cell lines. Curr Biol 5:283-295. CrossRef Medline

Bading H (2013) Nuclear calcium signalling in the regulation of brain function. Nat Rev Neurosci 14:593-608. CrossRef Medline

Ballou LM, Lin RZ (2008) Rapamycin and mTOR kinase inhibitors. J Chem Biol 1:27-36. CrossRef Medline

Banks A, Vincent J, Anyakoha C (2008) A review of particle swarm optimization. Part II: hybridisation, combinatorial, multicriteria and constrained optimization, and indicative applications. Nat Comput 7:109-124. CrossRef

Belelovsky K, Elkobi A, Kaphzan H, Nairn AC, Rosenblum K (2005) A molecular switch for translational control in taste memory consolidation. Eur J Neurosci 22:2560-2568. CrossRef Medline

Bengtson CP, Kaiser M, Obermayer J, Bading H (2013) Calcium responses to synaptically activated bursts of action potentials and their synapseindependent replay in cultured networks of hippocampal neurons. Biochim Biophys Acta 1833:1672-1679. CrossRef Medline

Browne GJ, Finn SG, Proud CG (2004) Stimulation of the AMP-activated protein kinase leads to activation of eukaryotic elongation factor 2 kinase and to its phosphorylation at a novel site, serine 398. J Biol Chem 279: 12220-12231. CrossRef Medline

Caloca MJ, Zugaza JL, Bustelo XR (2003) Exchange factors of the RasGRP family mediate Ras activation in the Golgi. J Biol Chem 278:33465-33473. CrossRef Medline

Carroll M, Warren O, Fan X, Sossin WS (2004) 5-HT stimulates eEF2 dephosphorylation in a rapamycin-sensitive manner in Aplysia neurites. J Neurochem 90:1464-1476. CrossRef Medline

Chang JW, Arnold MM, Rozenbaum A, Caputo A, Schweizer FE, Huynh M, Mathern GW, Sarafian TA, Watson JB (2012) Synaptoneurosome micromethod for fractionation of mouse and human brain, and primary neuronal cultures. J Neurosci Methods 211:289-295. CrossRef Medline

Cool B, Zinker B, Chiou W, Kifle L, Cao N, Perham M, Dickinson R, Adler A, Gagne G, Iyengar R, Zhao G, Marsh K, Kym P, Jung P, Camp HS, Frevert E (2006) Identification and characterization of a small molecule AMPK activator that treats key components of type 2 diabetes and the metabolic syndrome. Cell Metab 3:403-416. CrossRef Medline

Costa-Mattioli M, Sossin WS, Klann E, Sonenberg N (2009) Translational control of long-lasting synaptic plasticity and memory. Neuron 61:10-26. CrossRef Medline

Dagon Y, Avraham Y, Magen I, Gertler A, Ben-Hur T, Berry EM (2005) Nutritional status, cognition, and survival: a new role for leptin and AMP kinase. J Biol Chem 280:42142-42148. CrossRef Medline

Dash PK, Orsi SA, Moore AN (2006) Spatial memory formation and memory-enhancing effect of glucose involves activation of the tuberous sclerosis complex-Mammalian target of rapamycin pathway. J Neurosci 26:8048-8056. CrossRef Medline
Desai NS (2003) Homeostatic plasticity in the CNS: synaptic and intrinsic forms. J Physiol Paris 97:391-402. CrossRef Medline

Di Ventura B, Lemerle C, Michalodimitrakis K, Serrano L (2006) From in vivo to in silico biology and back. Nature 443:527-533. CrossRef Medline

Faas GC, Raghavachari S, Lisman JE, Mody I (2011) Calmodulin as a direct detector of $\mathrm{Ca} 2+$ signals. Nat Neurosci 14:301-304. CrossRef Medline

Fonseca BD, Alain T, Finestone LK, Huang BP, Rolfe M, Jiang T, Yao Z, Hernandez G, Bennett CF, Proud CG (2011) Pharmacological and genetic evaluation of proposed roles of mitogen-activated protein kinase/ extracellular signal-regulated kinase kinase (MEK), extracellular signalregulated kinase (ERK), and p90(RSK) in the control of mTORC1 protein signaling by phorbol esters. J Biol Chem 286:27111-27122. CrossRef Medline

Gal-Ben-Ari S, Kenney JW, Ounalla-Saad H, Taha E, David O, Levitan D, Gildish I, Panja D, Pai B, Wibrand K, Simpson TI, Proud CG, Bramham CR, Armstrong JD, Rosenblum K (2012) Consolidation and translation regulation. Learn Mem 19:410-422. CrossRef Medline

Gildish I, Manor D, David O, Sharma V, Williams D, Agarwala U, Wang X, Kenney JW, Proud CG, Rosenblum K (2012) Impaired associative taste learning and abnormal brain activation in kinase-defective eEF2K mice. Learn Mem 19:116-125. CrossRef Medline

Göransson O, McBride A, Hawley SA, Ross FA, Shpiro N, Foretz M, Viollet B, Hardie DG, Sakamoto K (2007) Mechanism of action of A-769662, a valuable tool for activation of AMP-activated protein kinase. J Biol Chem 282:32549-32560. CrossRef Medline

Guigas B, Sakamoto K, Taleux N, Reyna SM, Musi N, Viollet B, Hue L (2009) Beyond AICA riboside: in search of new specific AMP-activated protein kinase activators. IUBMB Life 61:18-26. CrossRef Medline

Gulati P, Gaspers LD, Dann SG, Joaquin M, Nobukuni T, Natt F, Kozma SC, Thomas AP, Thomas G (2008) Amino acids activate mTOR Complexl via $\mathrm{Ca} 2+/ \mathrm{CaM}$ signaling to hVps34. Cell Metab 7:456-465. CrossRef Medline

Hardingham GE, Bading H (2010) Synaptic versus extrasynaptic NMDA receptor signalling: implications for neurodegenerative disorders. Nat Rev Neurosci 11:682-696. CrossRef Medline

Hardingham GE, Fukunaga Y, Bading H (2002) Extrasynaptic NMDARs oppose synaptic NMDARs by triggering CREB shut-off and cell death pathways. Nat Neurosci 5:405-414. CrossRef Medline

Hawley SA, Pan DA, Mustard KJ, Ross L, Bain J, Edelman AM, Frenguelli BG, Hardie DG (2005) Calmodulin-dependent protein kinase kinase-beta is an alternative upstream kinase for AMP-activated protein kinase. Cell Metab 2:9-19. CrossRef Medline

Heise C, Gardoni F, Culotta L, di Luca M, Verpelli C, Sala C (2014) Elongation factor-2 phosphorylation in dendrites and the regulation of dendritic mRNA translation in neurons. Front Cell Neurosci 8:35. CrossRef Medline

Hizli AA, Chi Y, Swanger J, Carter JH, Liao Y, Welcker M, Ryazanov AG, Clurman BE (2013) Phosphorylation of eukaryotic elongation factor 2 (eEF2) by cyclin A-cyclin-dependent kinase 2 regulates its inhibition by eEF2 kinase. Mol Cell Biol 33:596-604. CrossRef Medline

Horman S, Beauloye C, Vertommen D, Vanoverschelde JL, Hue L, Rider MH (2003) Myocardial ischemia and increased heart work modulate the phosphorylation state of eukaryotic elongation factor-2. J Biol Chem 278: 41970-41976. CrossRef Medline

Hornberg JJ, Bruggeman FJ, Binder B, Geest CR, de Vaate AJ, Lankelma J, Heinrich R, Westerhoff HV (2005) Principles behind the multifarious control of signal transduction. ERK phosphorylation and kinase/phosphatase control. FEBS J 272:244-258. CrossRef Medline

Hui L, Rodrik V, Pielak RM, Knirr S, Zheng Y, Foster DA (2005) mTORdependent suppression of protein phosphatase $2 \mathrm{~A}$ is critical for phospholipase D survival signals in human breast cancer cells. J Biol Chem 280: 35829-35835. CrossRef Medline

Huynh H, Soo KC, Chow PK, Tran E (2007) Targeted inhibition of the extracellular signal-regulated kinase kinase pathway with AZD6244 (ARRY-142886) in the treatment of hepatocellular carcinoma. Mol Cancer Ther 6:138-146. CrossRef Medline

Im HI, Nakajima A, Gong B, Xiong X, Mamiya T, Gershon ES, Zhuo M, Tang YP (2009) Post-training dephosphorylation of eEF-2 promotes protein synthesis for memory consolidation. PLoS One 4:e7424. CrossRef Medline

Inamura N, Nawa H, Takei N (2005) Enhancement of translation elongation in neurons by brain-derived neurotrophic factor: implications for 
mammalian target of rapamycin signaling. J Neurochem 95:1438-1445. CrossRef Medline

Inoki K, Zhu T, Guan KL (2003) TSC2 mediates cellular energy response to control cell growth and survival. Cell 115:577-590. CrossRef Medline

Kanhema T, Dagestad G, Panja D, Tiron A, Messaoudi E, Håvik B, Ying SW, Nairn AC, Sonenberg N, Bramham CR (2006) Dual regulation of translation initiation and peptide chain elongation during BDNF-induced LTP in vivo: evidence for compartment-specific translation control. J Neurochem 99:1328-1337. CrossRef Medline

Kelleher RJ 3rd, Govindarajan A, Jung HY, Kang H, Tonegawa S (2004) Translational control by MAPK signaling in long-term synaptic plasticity and memory. Cell 116:467-479. CrossRef Medline

Kenney JW, Moore CE, Wang X, Proud CG (2014) Eukaryotic elongation factor 2 kinase, an unusual enzyme with multiple roles. Adv Biol Regul 55:15-27. CrossRef Medline

Kimura N, Tokunaga C, Dalal S, Richardson C, Yoshino K, Hara K, Kemp BE, Witters LA, Mimura O, Yonezawa K (2003) A possible linkage between AMP-activated protein kinase (AMPK) and mammalian target of rapamycin (mTOR) signalling pathway. Genes Cells 8:65-79. CrossRef Medline

Le Novère N, Hucka M, Mi H, Moodie S, Schreiber F, Sorokin A, Demir E, Wegner K, Aladjem MI, Wimalaratne SM, Bergman FT, Gauges R, Ghazal P, Kawaji H, Li L, Matsuoka Y, Villéger A, Boyd SE, Calzone L, Courtot M, Dogrusoz U, et al. (2009) The systems biology graphical notation. Nat Biotechnol 27:735-741. CrossRef Medline

Lee B, Butcher GQ, Hoyt KR, Impey S, Obrietan K (2005) Activitydependent neuroprotection and cAMP response element-binding protein (CREB): kinase coupling, stimulus intensity, and temporal regulation of CREB phosphorylation at serine 133. J Neurosci 25:1137-1148. CrossRef Medline

Lenz G, Avruch J (2005) Glutamatergic regulation of the p70S6 kinase in primary mouse neurons. J Biol Chem 280:38121-38124. CrossRef Medline

Leprivier G, Remke M, Rotblat B, Dubuc A, Mateo AR, Kool M, Agnihotri S, El-Naggar A, Yu B, Somasekharan SP, Faubert B, Bridon G, Tognon CE, Mathers J, Thomas R, Li A, Barokas A, Kwok B, Bowden M, Smith $S$, et al. (2013) The eEF2 kinase confers resistance to nutrient deprivation by blocking translation elongation. Cell 153:1064-1079. CrossRef Medline

Li H, Rao A, Hogan PG (2011) Interaction of calcineurin with substrates and targeting proteins. Trends Cell Biol 21:91-103. CrossRef Medline

Ma L, Chen Z, Erdjument-Bromage H, Tempst P, Pandolfi PP (2005) Phosphorylation and functional inactivation of TSC2 by Erk implications for tuberous sclerosis and cancer pathogenesis. Cell 121:179-193. CrossRef Medline

Maravall M, Mainen ZF, Sabatini BL, Svoboda K (2000) Estimating intracellular calcium concentrations and buffering without wavelength ratioing. Biophys J 78:2655-2667. CrossRef Medline

Marino S, Hogue IB, Ray CJ, Kirschner DE (2008) A methodology for performing global uncertainty and sensitivity analysis in systems biology. J Theor Biol 254:178-196. CrossRef Medline

Moles CG, Mendes P, Banga JR (2003) Parameter estimation in biochemical pathways: a comparison of global optimization methods. Genome Res 13:2467-2474. CrossRef Medline

Nairn AC, Palfrey HC (1987) Identification of the major Mr 100,000 substrate for calmodulin-dependent protein kinase III in mammalian cells as elongation factor-2. J Biol Chem 262:17299-17303. Medline

Narayanan U, Nalavadi V, Nakamoto M, Pallas DC, Ceman S, Bassell GJ, Warren ST (2007) FMRP phosphorylation reveals an immediate-early signaling pathway triggered by group I mGluR and mediated by PP2A. J Neurosci 27:14349-14357. CrossRef Medline

Park S, Park JM, Kim S, Kim JA, Shepherd JD, Smith-Hicks CL, Chowdhury S, Kaufmann W, Kuhl D, Ryazanov AG, Huganir RL, Linden DJ, Worley PF (2008) Elongation factor 2 and fragile $\mathrm{X}$ mental retardation protein control the dynamic translation of Arc/Arg3.1 essential for mGluR-LTD. Neuron 59:70-83. CrossRef Medline

Pende M, Um SH, Mieulet V, Sticker M, Goss VL, Mestan J, Mueller M, Fumagalli S, Kozma SC, Thomas G (2004) S6K1(-/-)/S6K2(-/-) mice exhibit perinatal lethality and rapamycin-sensitive $5^{\prime}$-terminal oligopyrimidine $\mathrm{mRNA}$ translation and reveal a mitogen-activated protein kinase-dependent S6 kinase pathway. Mol Cell Biol 24:3112-3124. CrossRef Medline

Petrozzino JJ, Pozzo Miller LD, Connor JA (1995) Micromolar Ca2 + transients in dendritic spines of hippocampal pyramidal neurons in brain slice. Neuron 14:1223-1231. CrossRef Medline

Pokorska A, Vanhoutte P, Arnold FJ, Silvagno F, Hardingham GE, Bading H (2003) Synaptic activity induces signalling to CREB without increasing global levels of cAMP in hippocampal neurons. J Neurochem 84:447452. CrossRef Medline

Potter WB, O'Riordan KJ, Barnett D, Osting SM, Wagoner M, Burger C, Roopra A (2010) Metabolic regulation of neuronal plasticity by the energy sensor AMPK. PLoS One 5:e8996. CrossRef Medline

Price NT, Redpath NT, Severinov KV, Campbell DG, Russell JM, Proud CG (1991) Identification of the phosphorylation sites in elongation factor-2 from rabbit reticulocytes. FEBS Lett 282:253-258. CrossRef Medline

Pyr Dit Ruys S, Wang X, Smith EM, Herinckx G, Hussain N, Rider MH, Vertommen D, Proud CG (2012) Identification of autophosphorylation sites in eukaryotic elongation factor-2 kinase. Biochem J 442:681-692. CrossRef Medline

Redpath NT, Proud CG (1993) Cyclic AMP-dependent protein kinase phosphorylates rabbit reticulocyte elongation factor- 2 kinase and induces calcium-independent activity. Biochem J 293:31-34. Medline

Redpath NT, Price NT, Severinov KV, Proud CG (1993) Regulation of elongation factor-2 by multisite phosphorylation. Eur J Biochem 213:689_ 699. CrossRef Medline

Romero-Ruiz A, Bautista L, Navarro V, Heras-Garvín A, March-Díaz R, Castellano A, Gómez-Diaz R, Castro MJ, Berra E, López-Barneo J, Pascual A (2012) Prolyl hydroxylase-dependent modulation of eukaryotic elongation factor 2 activity and protein translation under acute hypoxia. J Biol Chem 287:9651-9658. CrossRef Medline

Ronnett GV, Ramamurthy S, Kleman AM, Landree LE, Aja S (2009) AMPK in the brain: its roles in energy balance and neuroprotection. J Neurochem [Suppl 109] 1:17-23. CrossRef Medline

Roux PP, Ballif BA, Anjum R, Gygi SP, Blenis J (2004) Tumor-promoting phorbol esters and activated Ras inactivate the tuberous sclerosis tumor suppressor complex via p90 ribosomal S6 kinase. Proc Natl Acad Sci U S A 101:13489-13494. CrossRef Medline

Ryazanov AG, Natapov PG, Shestakova EA, Severin FF, Spirin AS (1988) Phosphorylation of the elongation factor 2: the fifth Ca2+/calmodulindependent system of protein phosphorylation. Biochimie 70:619-626. CrossRef Medline

Sanders MJ, Ali ZS, Hegarty BD, Heath R, Snowden MA, Carling D (2007) Defining the mechanism of activation of AMP-activated protein kinase by the small molecule A-769662, a member of the thienopyridone family. J Biol Chem 282:32539-32548. CrossRef Medline

Schmidt H, Jirstrand M (2006) Systems Biology Toolbox for MATLAB: a computational platform for research in systems biology. Bioinformatics 22:514-515. CrossRef Medline

Sutton MA, Taylor AM, Ito HT, Pham A, Schuman EM (2007) Postsynaptic decoding of neural activity: eEF2 as a biochemical sensor coupling miniature synaptic transmission to local protein synthesis. Neuron 55:648661. CrossRef Medline

Sweatt JD (2004) Mitogen-activated protein kinases in synaptic plasticity and memory. Curr Opin Neurobiol 14:311-317. CrossRef Medline

Takei N, Kawamura M, Ishizuka Y, Kakiya N, Inamura N, Namba H, Nawa H (2009) Brain-derived neurotrophic factor enhances the basal rate of protein synthesis by increasing active eukaryotic elongation factor 2 levels and promoting translation elongation in cortical neurons. J Biol Chem 284:26340-26348. CrossRef Medline

Tavares CD, O'Brien JP, Abramczyk O, Devkota AK, Shores KS, Ferguson SB, Kaoud TS, Warthaka M, Marshall KD, Keller KM, Zhang Y, Brodbelt JS, Ozpolat B, Dalby KN (2012) Calcium/calmodulin stimulates the autophosphorylation of elongation factor 2 kinase on Thr-348 and Ser-500 to regulate its activity and calcium dependence. Biochemistry 51:2232-2245. CrossRef Medline

Terai K, Hiramoto Y, Masaki M, Sugiyama S, Kuroda T, Hori M, Kawase I, Hirota H (2005) AMP-activated protein kinase protects cardiomyocytes against hypoxic injury through attenuation of endoplasmic reticulum stress. Mol Cell Biol 25:9554-9575. CrossRef Medline

Verpelli C, Piccoli G, Zibetti C, Zanchi A, Gardoni F, Huang K, Brambilla D, Di Luca M, Battaglioli E, Sala C (2010) Synaptic activity controls den- 
dritic spine morphology by modulating eEF2-dependent BDNF synthesis. J Neurosci 30:5830-5842. CrossRef Medline

Wang JQ, Fibuch EE, Mao L (2007) Regulation of mitogen-activated protein kinases by glutamate receptors. J Neurochem 100:1-11. CrossRef Medline

Wang L, Proud CG (2002) Regulation of the phosphorylation of elongation factor 2 by MEK-dependent signalling in adult rat cardiomyocytes. FEBS Lett 531:285-289. CrossRef Medline

Wang X, Li W, Williams M, Terada N, Alessi DR, Proud CG (2001) Regulation of elongation factor 2 kinase by p90(RSK1) and p70 S6 kinase. EMBO J 20:4370-4379. CrossRef Medline

Weatherill DB, McCamphill PK, Pethoukov E, Dunn TW, Fan X, Sossin WS
(2011) Compartment-specific, differential regulation of eukaryotic elongation factor 2 and its kinase within Aplysia sensory neurons. J Neurochem 117:841-855. CrossRef Medline

Wong HK, Fricker M, Wyttenbach A, Villunger A, Michalak EM, Strasser A, Tolkovsky AM (2005) Mutually exclusive subsets of BH3-only proteins are activated by the p53 and c-Jun N-terminal kinase/c-Jun signaling pathways during cortical neuron apoptosis induced by arsenite. Mol Cell Biol 25:8732-8747. CrossRef Medline

Woods A, Dickerson K, Heath R, Hong SP, Momcilovic M, Johnstone SR, Carlson M, Carling D (2005) Ca2+/calmodulin-dependent protein kinase kinase-beta acts upstream of AMP-activated protein kinase in mammalian cells. Cell Metab 2:21-33. CrossRef Medline 